\title{
Article
}

\section{Interactive relighting, digital image enhancement and inclusive diagrammatic representations for the analysis of rock art superimposition: The main Pleito cave (CA, USA)}

Kotoula, Eleni, Robinson, David Wayne and Bedford, Clare Available at http://clok.uclan.ac.uk/21944/

Kotoula, Eleni, Robinson, David Wayne ORCID: 0000-0002-0729-5011 and Bedford, Clare ORCID: 0000-0002-6897-3293 (2018) Interactive relighting, digital image enhancement and inclusive diagrammatic representations for the analysis of rock art superimposition: The main Pleito cave (CA, USA). Journal of Archaeological Science, 93 . pp. 26-41. ISSN 0305-4403

It is advisable to refer to the publisher's version if you intend to cite from the work. http://dx.doi.org/10.1016/j.jas.2018.02.012

For more information about UCLan's research in this area go to

http://www.uclan.ac.uk/researchgroups/ and search for < name of research Group>.

For information about Research generally at UCLan please go to http://www.uclan.ac.uk/research/

All outputs in CLoK are protected by Intellectual Property Rights law, including Copyright law. Copyright, IPR and Moral Rights for the works on this site are retained by the individual authors and/or other copyright owners. Terms and conditions for use of this material are defined in the policies page. 
1 INTERACTIVE RELIGHTING, DIGITAL IMAGE ENHANCEMENT AND

2 INCLUSIVE DIAGRAMMATIC REPRESENTATIONS FOR THE ANALYSIS OF

3 ROCK ART SUPERIMPOSITION: THE MAIN PLEITO CAVE (CA, USA)

4 Kotoula, E., Robinson, D.W., Bedford, C.

5 School of Forensic \& Applied Sciences, University of Central Lancashire, Preston, United Kingdom, PR1 2HE

6 Abstract

7 This paper deals with the documentation, and virtual visual analysis of pictographs using

8 interactive relighting, digital image enhancement techniques and diagrammatic

9 representations. It discusses areas of interest for the analysis of low surface detail, large and

10 geometrically complex superimposed pictographs. The synergy of reflectance transformation imaging (RTI) and decorrelation stretch (DS) aimed to improve the study of superimposition via the enhanced visualization of the surface morphology, dominant features, paint characteristics and layering. Additionally, diagrammatic representations of the results of the image-based analysis provided a valuable tool for interpretation and integration of the diverse dataset from the ongoing research in the Pleito Cave in California. This method allows revisiting unresolved hypotheses concerning the site by unpacking chemical and visual data in superimposed sequences.

Keywords: interactive relighting, RTI, dStretch, rock art, stratigraphic diagrams, DOT, GraphViz

\section{Highlights}

- Applications of RTI to the study of pictographs are described.

- Synergy of RTI and DStretch is proposed for the study of complex superimposed pictographs.

- Directed graphs are proposed for integration of diverse rock art data. 

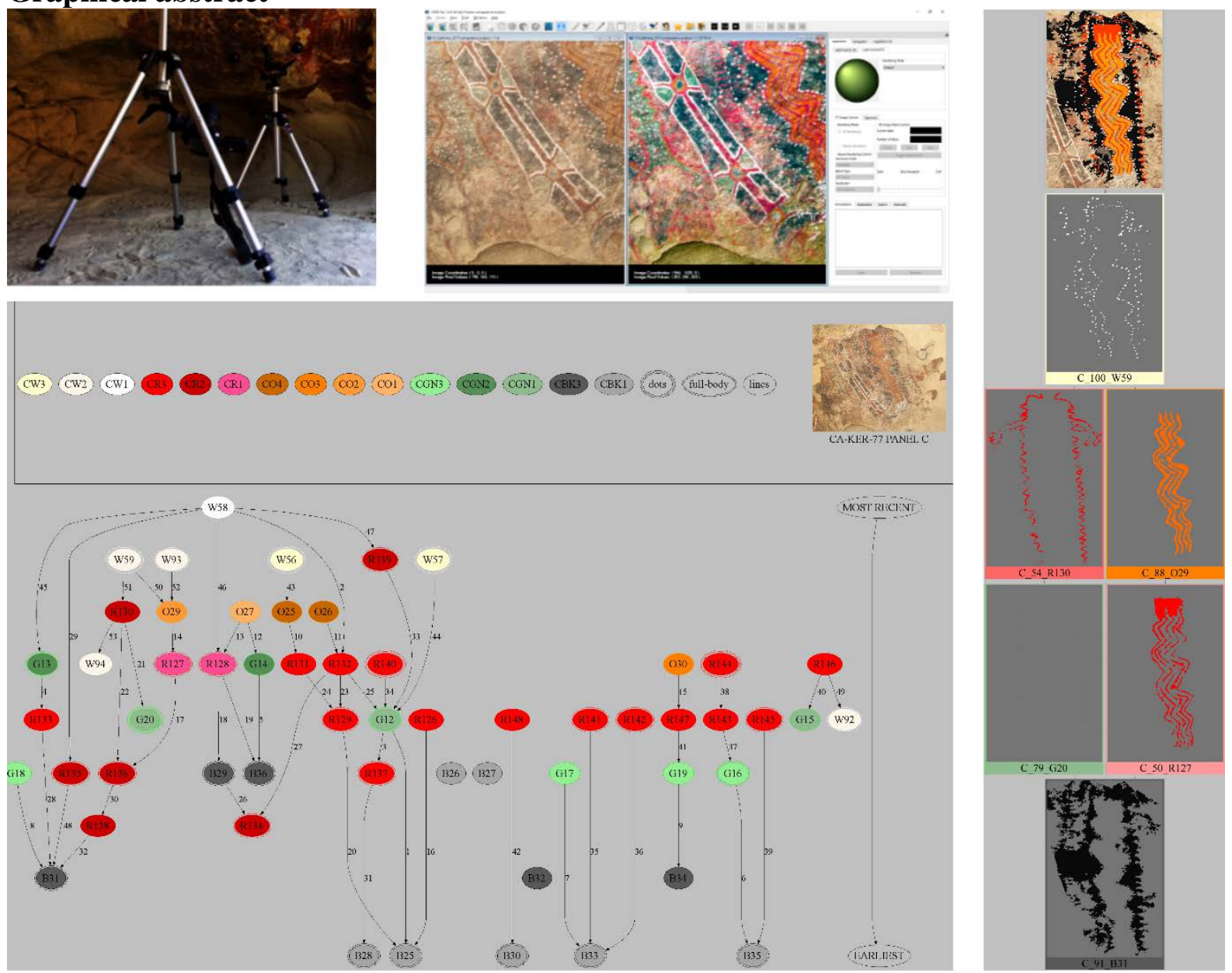

\section{Introduction}

Digital imaging techniques, including decorrelation stretch (DS), combined with 3D technologies have been applied extensively to rock art (Cerrillo-Cuenca and Sepúlveda, 2015; Defrasne, 2014; Domingo et al., 2015; Cobb, 2016; Fritz et al., 2016; Gunn et al., 2010; McDonald et al., 2016; Poier et al., 2016; Robert et al., 2016; Rogerio-Candelera, 2016, 2015). RTI technology (Malzbender et al., 2001; Mudge et al., 2005) has received less attention for analysis of pictographs, although previous work proved that surface details can be thoroughly studied, unnoticed evidence can be revealed and engravings, reworking, erasure, and sequences of working history can be examined, assisting in defining earlier elements relative to later ones. RTI archaeological applications focused on petroglyphs (Duffy, 2010; Mudge et al., 2006; Riris and Corteletti, 2014), engraved details on stone and (Díaz-Guardamino et al., 2015; Gabov and Bevan, 2011; Jones et al., 2015; Lehoux, 2013; Milner et al., 2016) and painted artefacts (Artal-Isbrand and Klausmeyer, 2015; Beale et al., 2013; Kotoula and Earl, 2015; Kotoula, 2016; Padfield et al., 2005). This paper presents the results of the first application of interactive relighting in synergy with digital image enhancement techniques to the study of pictographs, with an emphasis on the analysis of rock art superimposition. It discusses the problems encountered during data capture, processing and analysis and the way they were addressed. It presents the potential of RTI documentation and analysis of superimposed pictographs, focusing on condition assessment, visualization of surface morphology, dominant features, paint characteristics and layering, as well as the limitations of the technique. Then, it discusses the requirements, evaluates the already 
available systems and develops a visual grammar for the holistic diagrammatic representation of multimodal diverse rock art dataset based on DOT scripts rendered in GraphViz.

Diagrams facilitate externalization and organization of thoughts, communication, and justification of ideas, insights and enhanced detection of patterns via synthesis of large and diverse datasets by abstract representation. They can be revised, manipulated and interpreted in different meaningful ways via visual perception (Eades, 2014; Goel et al., 2010; Moktefi and Shin, 2013; Tversky, 2014). The combination of schematic representations in a conceptual ordering forms visual narrative and explains sequential information. For archaeology, the Harris Matrix is a set of rules for the generation of diagrams enriched with stratigraphic information (Harris, 1989), used for documentation of analysis and conservation (Barros García, 2009; Watts et al., 2002) and for rock art superposition studies (Chippindale et al., 2000; Mguni, 1997), informed by imaging analysis (Gunn et al., 2010). The recent development of portable technologies for compositional analysis of pigments and digital image enhancement in synergy with colour and texture visualization for the analysis of rock art and superimposed pigment motifs leads to complex multimodal datasets (Robinson et al., 2015), that need to be integrated into the stratigraphic diagrams. The currently available specialized pieces of software, ArchEd (Hundack et al., 1998), Stratify (Herzog, 2004), compatible with Strati5 (Sikora et al., 2016), and Harris Matrix Composer (Traxler and Neubauer, 2008), do not provide useful options for differentiation of painted features, represented by nodes. Hence, it is difficult to incorporate additional information, apart from the stratigraphic relationships between painting features. Many aspects of the paintings, such as pigments and paint application methods used, can be represented diagrammatically via differentiation of nodes in terms of shapes, outline styles and colours. Alternatively, diagrams can be generated from text via scripts programmatically, such as Unified Modelling Language (UML) (Booch et al., 1999) and DOT for GraphViz (Gansner et al., 2015; Khoury, 2013). The former may be problematic in the case of many nodes with complex relationships, which is usually the case in rock art. On the contrary, directed graphs generated by the DOT language scripts in GraphViz, an open source graph visualization software and automatic layout system, provide options for adjusting the representation and placement of subgraphs, nodes, and edges. DOT is a very well documented programming language with an active support community of developers. It has been used for automatic generation of Harris Matrices in excavations such as the case of Gortyna, Crete (Costa, 2007), and have been incorporated in excavation management systems (De Roo et al., 2016; Motz and Carrier, 2013) and CIDOC-CRM mappings (Carver, 2013).

Surprisingly, very few studies of Pleito have addressed the complex superimposed paintings at the site. Drawing upon historical records, Lee (1979) famously hypothesized that the exotic blues and greens were stolen from coastal Franciscan Missions by Native refugees following a revolt by the Chumash in 1824. Similarly using ethnohistoric records, Whitley (2000: 121) interpreted some of the compositions as representing 'exploding shamans', or self-portraits of the bodily transformation shamans undergo during trance experiences. Superimposition is one of the most valuable aspects of rock art as it provides crucial relative data to determine sequencing of image making and change through time. Methods that enable us to gain as much information as possible from superimposed rock art provide means to address questions concerning time depth. When it comes to painted rock art, including information on texture, colour, and pigment composition allow for a multivariate analysis of 
change through time in addition to stylistic change. Both previous interpretations of Pleito are based upon ethnohistorical documents from the 1800s to 1900s and do not include superimposition analysis of paintings nor in situ analytical work on the paint itself. Here, we show how integrating RTI with in situ analytical work provides a powerful tool to address questions of sequence and pigment source, thus enhancing our understanding of the site itself.

\section{Materials}

The Pleito cave pictographs (CA-KER-77) located in the Wind Wolves Preserve in South Central California, USA, are characterized by the variety of shapes of polychrome multilayered compositions, that indicate the high levels of skill and knowledge of pigment preparation and application and by extension the importance of the cave (Robinson et al., 2015; Robinson, 2013a). Within the Main Cave, the extensive colour palette includes varieties of reds, yellows, oranges, whites/creams, greens, and blues: combined with the intensity of overpainting, Pleito stands out as one of the most complex painted indigenous sites in the Americas (Robinson et al. 2015; Grant 1965). Prior to interactive relighting and diagrammatic representation, a variety of techniques has been recently applied, such as analysis of pigments using X-ray fluorescence, FTIR and Raman spectroscopy, 3D digitization with laser scanning, digital image enhancement and study of superimposed pigment motifs with layer separation techniques (Bedford et al., 2016; Robinson et al., 2015). This study presents examples from pictorial elements located on the ceiling of the Main Cave (Panels B, C, D, E and J), with an emphasis on Panel C (Figure 1).

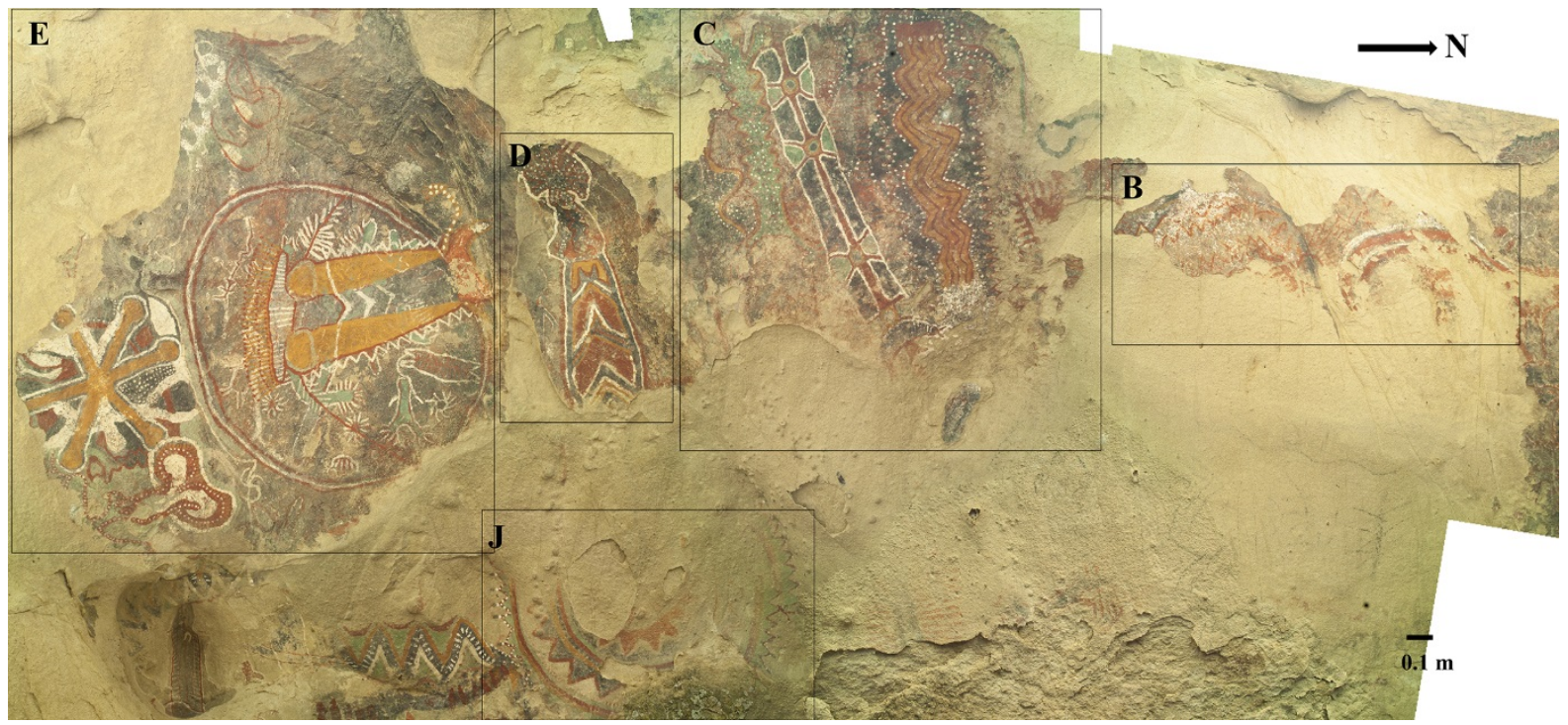

Figure 1: Panels B, C, D, E and J locations.

\section{Methods}

\subsection{RTI data acquisition, processing, and viewing}

Data acquisition was completed using the Highlight-based method (Cultural Heritage Imaging, 2013a; Duffy et al., 2013). Setting up the scene was more complicated than in typical outdoors RTI data capture because of the scale, dimensions and geometric complexity of the cave. The necessity to avoid any contact with the painted surface leaves limited space for humans and equipment. The geometric complexity of the cave introduced problems not only in setting up the scene but also during capture. Unlike typical RTI data acquisition sessions, where the series of raking and oblique light images form a complete hemisphere 
around the subject, in Pleito cave certain lighting positions are not accessible. As a result, the hemispherical coverage varies across the RTI datasets captured. After the acquisition of 49 RTI datasets and before processing using the RTIBuilder (Cultural Heritage Imaging, 2011), datasets were aligned using digital image processing software in order to improve the quality of the *.rti and *.ptm files and avoid blurry views due to the unstable floor of the cave. In addition, after the promising results of Decorrelation Stretch (DS) in Pleito cave and elsewhere, RTI datasets were preprocessed, using the DS plugin and Image J batch processing tools (Ferreira and Rasband, 2012; Harman, 2008). The DS RTI dataset were processed following the mainstream methodology, resulting in DS RTI files. The RTI files were viewed individually in RTIViewer (Cultural Heritage Imaging, 2013b) and analysed in a comparative mode in CHER-Ob (Shi et al., 2016) (Figure 2).
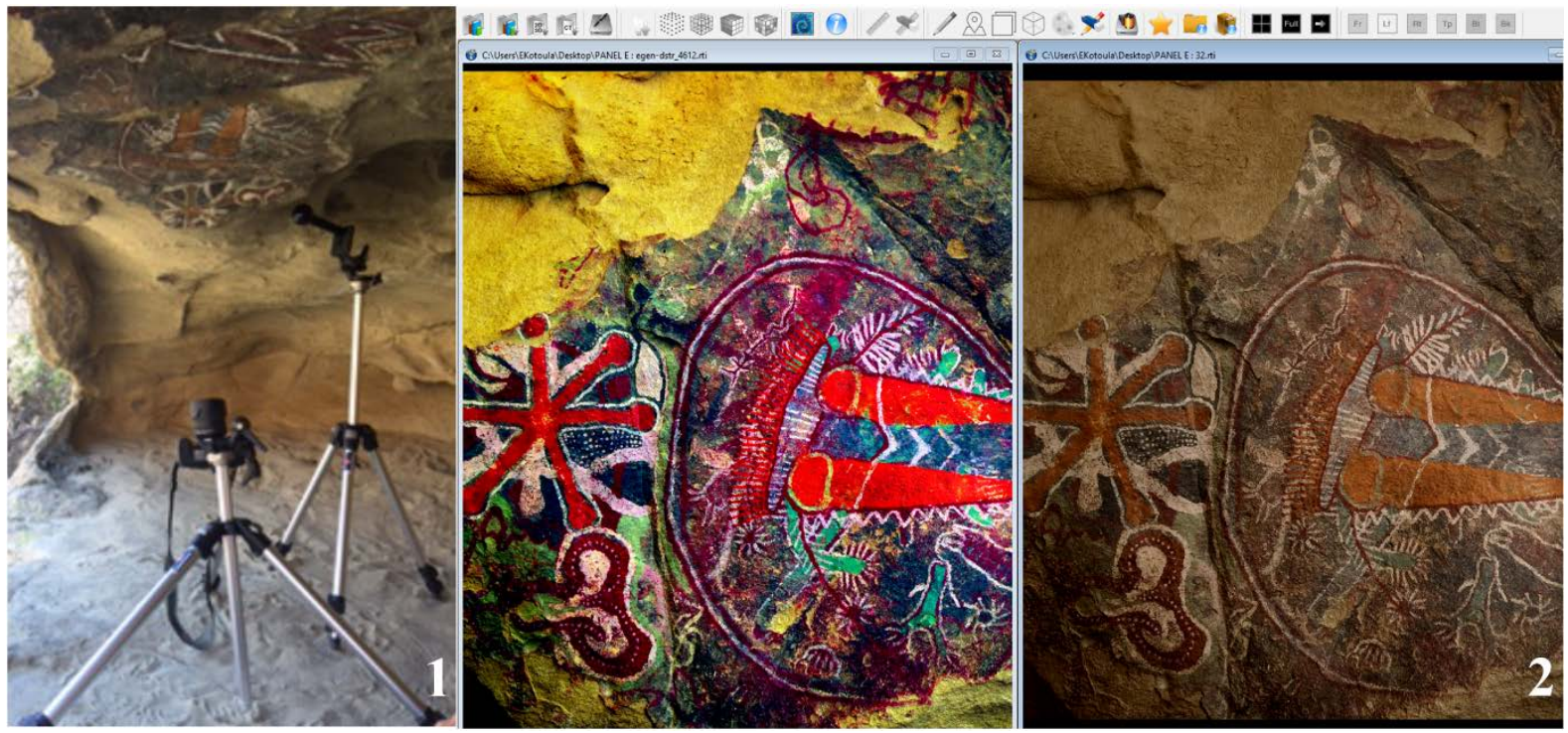

Figure 2: Data acquisition set up for data capture of Panel E, located on the ceiling of the cave (1). Comparative analysis of DS RTI and mainstream RTI of Panel E. Screenshot of $\mathrm{CHER}-\mathrm{Ob}(2)$.

\subsection{Identification of pictorial elements}

Different DS colour enhancement modes, applied to orthophotos of the panels, were created and used as slices in an Image J 2D stack. The scrollbar provided easy navigation between the different DS filters and the wand tool assisted the selection of pictorial elements based on their colour. The ROI Manager utility facilitated saving, renaming (in accordance with the naming convention) and adjusting the attributes, such as colour, of each pictorial element. Two or more pictorial elements formed a group of composite selection in cases of symmetrical and continuous lines or elements with great similarity. Hence, it is possible to achieve a detailed representation which includes every paint feature, while minimising the number of pictorial elements. After the selection of all paint features, the measure and list ROI Manager functionality was used, leading to an .xls sheet which presents the assigned name and colour of each selection, its location in the stack, as well as its area and perimeter values (Figure 3). 


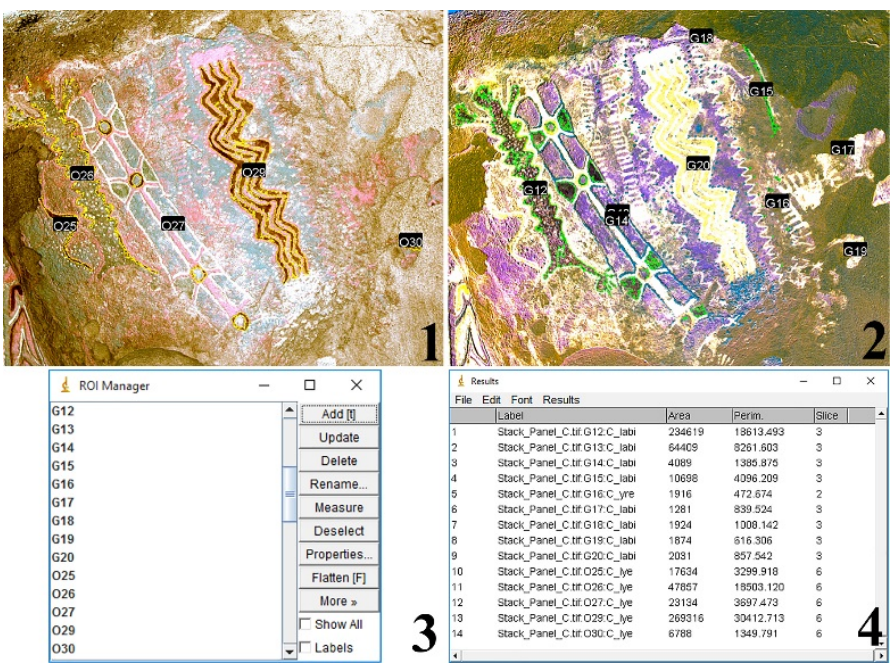

152 Figure 3: Screenshots of Image J. Digital image of Panel C in lye and labi DS mode, with 153 ROIs outlined in yellow and green colour (1,2). ROI Manager (3) and extracted results of 154 measurements (4).

\subsection{Exploring stratigraphic relationships}

156 A protocol for managing the interpretation of the *.rti and *.ptm files was set up. Analysis 157 began with the exploration of individual RTIs, in an attempt to define the general surface 158 morphology and the dominant features of paint texture, followed by the virtual assessment of 159 the state of preservation by identifying surface loss, detached edges, cracks, blisters, flaking, 160 delamination, and exfoliation. The interactive relighting analysis of panels continues with 161 comparisons of same colour features or areas with common background and preservation state. Lines crossed and covered by other lines, or elements painted on top of areas of loss were defined. Such information leads to the identification of earlier and later painting events and by extension to stratigraphic relationships between elements. Every stratigraphic relationship was simply recorded as pairs of below-above paint elements in .xls format, using the names assigned during the identification of pictorial elements and accompanied by a unique identifier number.

\subsection{Diagrammatic representation}

168 The alphanumeric values exported from ROI Manager during the identification of pictorial elements and the stratigraphic relationships recorded during the exploration of RTI files in .xls format were formatted using simple excel functions according to DOT language syntax and rendered in GraphViz as diagrams. The user assigns the diagram size, directionality, background colours, outline and line colours, font colours, fill colours, size, and shape of nodes, font size, width, and length of edges. Furthermore, diagrams included additional features, such as timeline, legend and titles/labels, as well as embedded 2D images. Considering the above, the use of GraphViz can potentially provide a solution for the diagrammatic representation of rock art research, incorporating the results of imaging and physicochemical analysis. Figure 4 presents a schema of the process followed for the generation of the diagrams. 


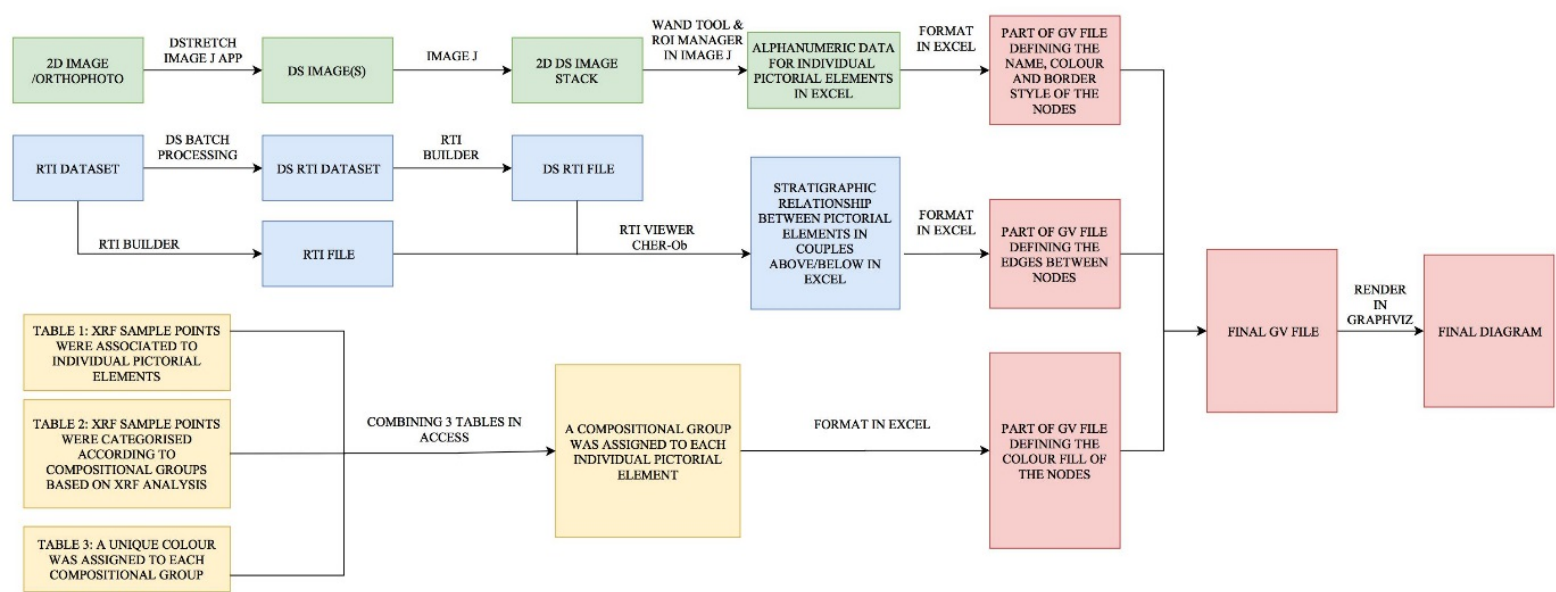

Figure 4: Schematic explanation of the methodology employed. Green colour indicates the process followed for the identification of pictorial elements based on DS images aligned in $2 D$ stack and further processed using the ROI Manager. Blue colour refers to the tasks completed for the generation of RTI files and the identification of stratigraphic relationships between pictorial elements. Yellow colour explains the methods used for the integration of $X R F$ and imaging results, by associating XRF sample points to pictorial elements and compositional groups. Red colour shows the provenance of the main components of a gv file, which can be rendered in Graphiz for the generation of an inclusive diagrammatic representation.

\section{Virtual visual analysis of pictographs via RTI}

\subsection{Condition assessment}

Physicochemical and biological weathering, as well as the impact of humans and animals, usually take the form of cracking, detachment, material loss, discoloration, and deposition. These weathering patterns, listed in the recommendations for rock art recording (Sharpe and Barnett, 2008) as well as in stone deterioration documentation guidelines (Vergès-Belmin, 2008), are evident in RTI images of the Pleito Cave panels. Detached edges, cracking, scaling, flaking and material loss phenomena were discernible since they introduce geometry transformations that are visible in normal maps and specular enhancement rendering mode. RTI provides an enhanced visualization of texture and perception of three-dimensionality that enables virtual visual assessment of the pictographs. Figure 5 presents examples of the RTI visualization of weathering patterns for Panel B and D, both located on the ceiling of the shelter, by comparing normal maps, specular enhancement renderings and DS RTI renderings. In the case of major geometric transformation phenomena, which are discernible in digital images, such as detached edges and losses, RTI visualizations are a more informative form of two-dimensional documentation. In the case of minor cracks and scaling transformations, RTI visualization succeeds in documentation contrary to static digital images. For the successful documentation and visual analysis of colour loss and discoloration, a combination of RTI in default and unsharp masking rendering modes and DS visualization is beneficial. The latter enhances the colour information, while the former depicts the colour as it appears to the naked eye but enriched with a detailed visualization of texture. RTI data acquisition is a non-contact methodology, which comes in accordance with preventive conservation measures. It assists in a more straightforward less time-consuming condition assessment. The resulting interactive files provide enhanced visualization of 
commonly observed weathering patterns and enable collaborative analysis. Although virtual condition assessment via RTI is beneficial, it is not a panacea and cannot substitute conventional methodologies. It is preferable to assess physically in situ the rock art sites for the understanding of nearby features, geomorphology of the cave, water routes etc.
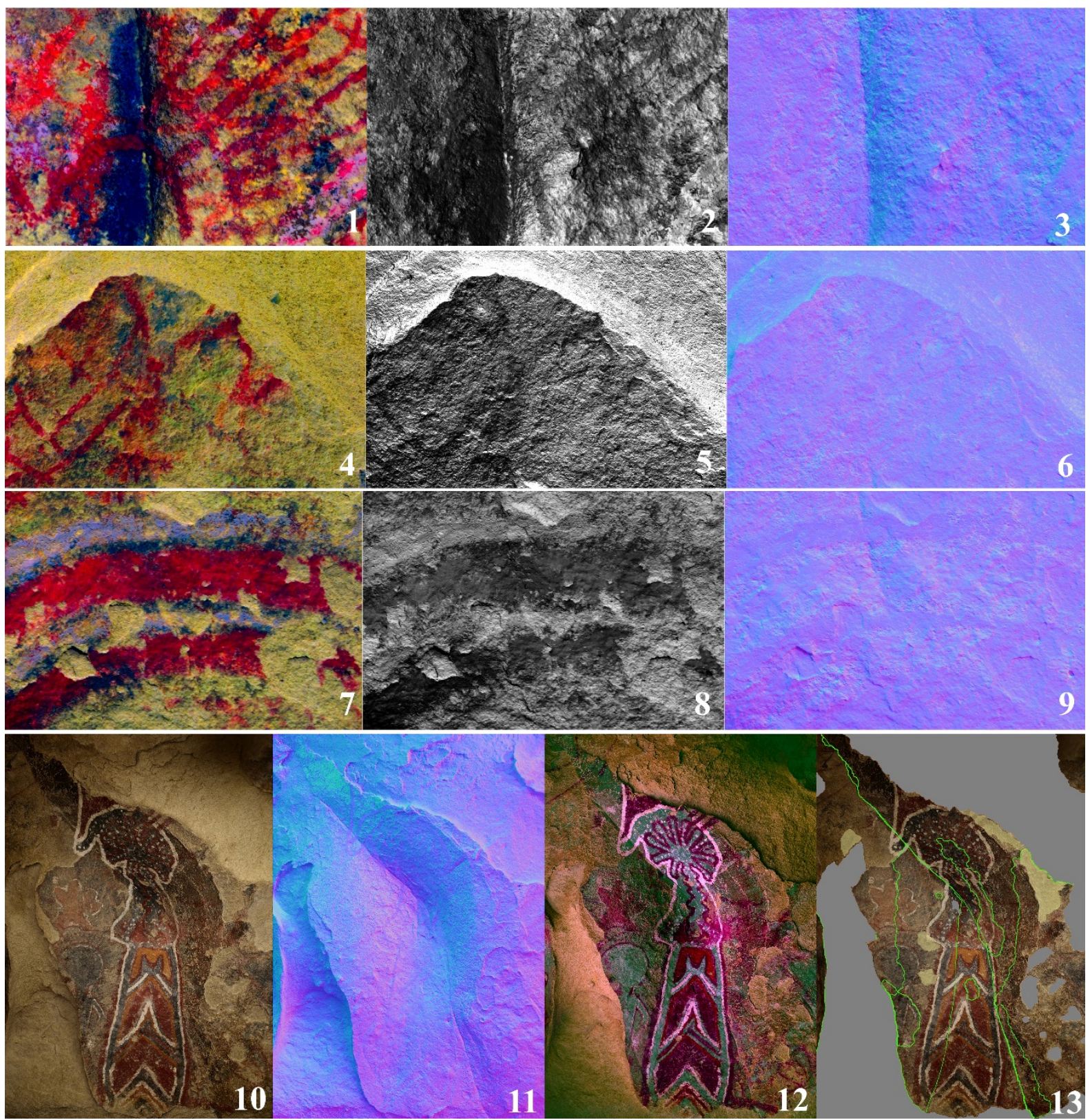

218 Figure 5: RTI visualization of weathering effects. Panel B, details, renderings in DS RTI mode $(1,4,7)$ specular enhancement $(2,5,8)$ and. normal maps $(3,6,9)$, Panel $D, R T I$ view as if lighted from above (10), normal map (11), rendering in DS RTI mode (12) and mapping of major geometric variation (green lines), material loss (grey filled areas) and minor surface anomalies (yellow filled areas) (13).

\subsection{Rock morphology}

224 RTI images provide an enhanced perception of the general morphology of the rock surface, compared to static 2D images. Hence, RTI is an alternative way to interpret the artist's intention regarding the shape of the rock. Although 3D modelling is the appropriate method for such exploration, it is worth mentioning that the software, hardware and storage 
requirements for RTIs are reasonably lower than 3D models. As shown in Figure 6, the digital images as if lighted from above present limited information about the general morphology of the rock. On the contrary, RTI visualizations provide enough details for understanding the shape of the rock. The most efficient way to demonstrate the potential of RTI visualization for the study of rock morphology is the comparison of a normal map with cross sections, modelled based on the photogrammetric 3D model of the Panel J, B and E.
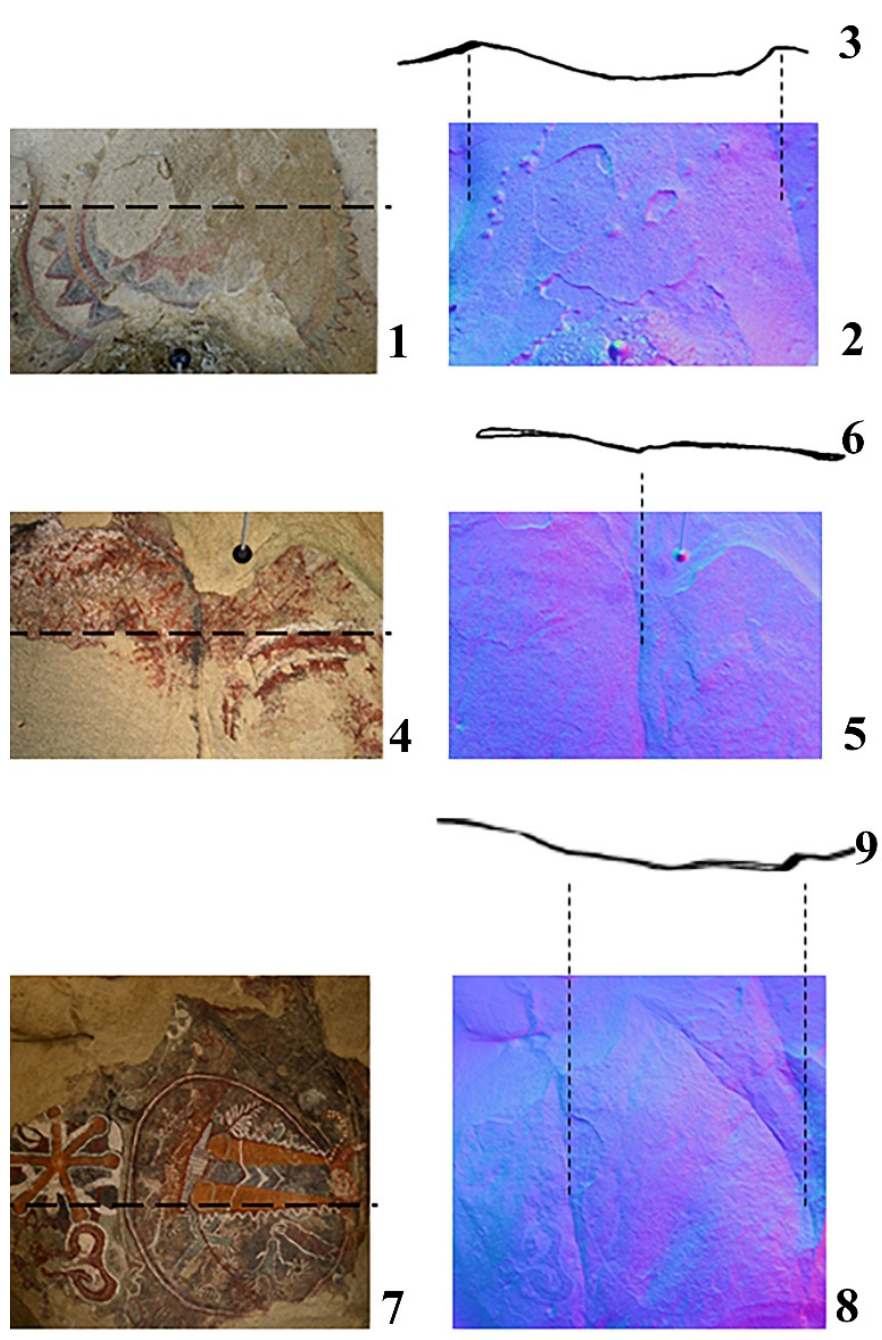

Figure 6: Panels $J(1), B(4)$ and $E(7)$ as if lighted from above, normal maps $(2,5,8)$ and cross sections of $3 D$ models $(3,6,9)$.

\subsection{Paint characteristics}

Importantly, RTI visualizations provide useful information for the study of the paint characteristics. RTI visualizations emphasize the three-dimensionality of the strokes. Unlike static 2D images, RTI views emphasize paint texture, thickness, application mode and preservation state. For example, in Panel E the white coloured pictorial elements are the dominant feature in terms of paint texture, clearly differentiated from other details based on the thickness, application mode and preservation state of the paint, as shown in Fig. 7. Although these white pictorial elements are clearly visible in static 2D image, the RTI views reveal their three-dimensionality. The observation of differences and similarities between pictorial elements in terms of paint characteristics, assists in distinguishing painting events. The white lines in parallel arrangement were painted with a thick colour and are different to the other white lines below the orange details, which appear less thick without clear three- 
249 dimensionality. These observations indicate the use of paint in different consistency as well 250 as a different paint application method.

251 Differences in paint characteristics provide evidence for identifying painting events even 252 when there is no direct superimposition. For example, in Panel D, the white outline of the 253 anthropomorph on the left and the white lines on the right are clearly visible in static 2D 254 images. Nevertheless, limited information about their paint characteristics, other than the 255 width, is observable. On the contrary the RTI views reveal their differences in terms of paint 256 application and state of preservation. As shown in the renderings in default mode and normal 257 map RTI visualization in Fig. 7, the white outline of the anthropomorph is not only less wide 258 but also painted with a thinner colour, which presents less cohesion with previous paint 259 layers. This observation provide evidence for identifying these two white pictorial elements 260 as different painting events. In addition, the similarities in the mode of colour application 261 indicate that pictorial elements are part of the same painting event, as in the case of the orange-red-white design in Panel D. Although most of these pictorial elements are

263 distinguishable in static 2D images, the option to acquire detailed views of colour and texture 
264 from RTI visualization and explore paint characteristics enhances the study of pictographs

265 significantly.
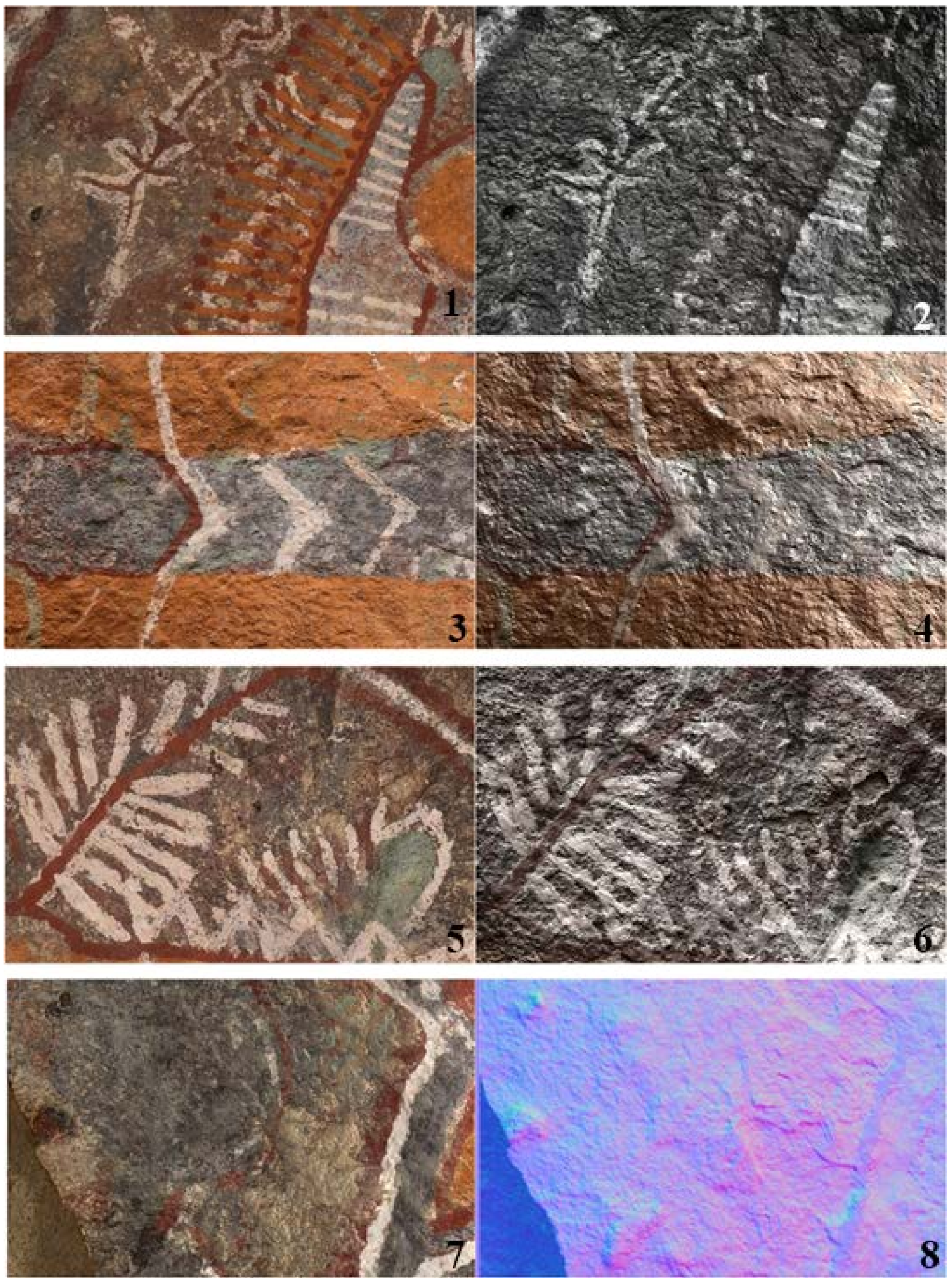

267 Figure 7: Panels E and D, details. RTI renderings as if lighted from above $(1,3,5,7)$ RTI visualizations in default rendering mode $(2,4,6)$ and normal map (8). 


\subsection{Layering}

RTI visualizes effectively the surface texture, emphasizing the three-dimensionality of strokes and by extension assisting in the study of layering, a key parameter for the superimposition analysis. In areas with faded colour details RTI views proved less informative. The best way to deal with this limitation and overcome this deficiency is to generate a DS RTI visualization, since results proved that DS RTI visualizations retain surface texture information and emphasize faded colour details.

For example, in Panel J, RTI renderings visualize the stratigraphic relationships of the painting features of the sun motif. Although from the view of the detail as lighted from above shown in Fig. 8.1 it is easily understandable that there is overlapping between the painting features, with the white dots as the most recent detail, it does not provide enough information for defining the stratigraphy of the motif. The RTI view in Fig. 8.2 is a detailed representation of the surface topography, including the subtle variation of the texture because of the paint strokes. Hence, RTI views provide evidence for defining the green line and the orange lines as the subsequent layer beneath the white dots, painted over the red and black details. The DS RTI view in this detail does not provide further information, other than a clearer visualization of paint features. On the contrary, the DS RTI technique proved particularly useful for the study of the stratigraphy of Panel B, due to the presence of a thin orange-yellow paint layer in different areas. This detail was hardly visible in mainstream RTI views, but distinguishable in DS RTI. Rendering the view in specular enhancement mode emphasized the three-dimensionality of the thin yellow-orange layer and provided evidence for defining this as a later addition to the panel. In the case of Panel D, as shown in the detail of Fig. 8.6-9, the RTI views emphasized the texture of the paint features. The orange and red details are painted on top of the red, on a black background. The DS RTI view makes the red details more discernible.

More examples that demonstrate the potential of DS RTI are given in Fig. 9. The RTI view on the detail of Panel D shown in Fig. 9.1 emphasizes the texture of the strokes and their stratigraphic relationship, but the DS RTI provided a clear view of the small curvy details of pale green and yellow colour. In Fig. 9.4. the red lines appear emphasized. The detail of Panel E in Fig. 9.6, shows that the DS RTI assisted in defining the stratigraphy of the red elements painted on the dark background and their relationship with the white lines. In fig. 9.8 the complex painting sequence of the detail from Panel B appears clearer in DS RTI mode. Application of RTI and DS independently and in synergy lead to the conclusion that the latter is a useful complementary technique for the study of superimposed pigment motifs in the case of elements with poor state of preservation or thin colour layers, which appear as shadows in digital images, and complex painting sequences. 

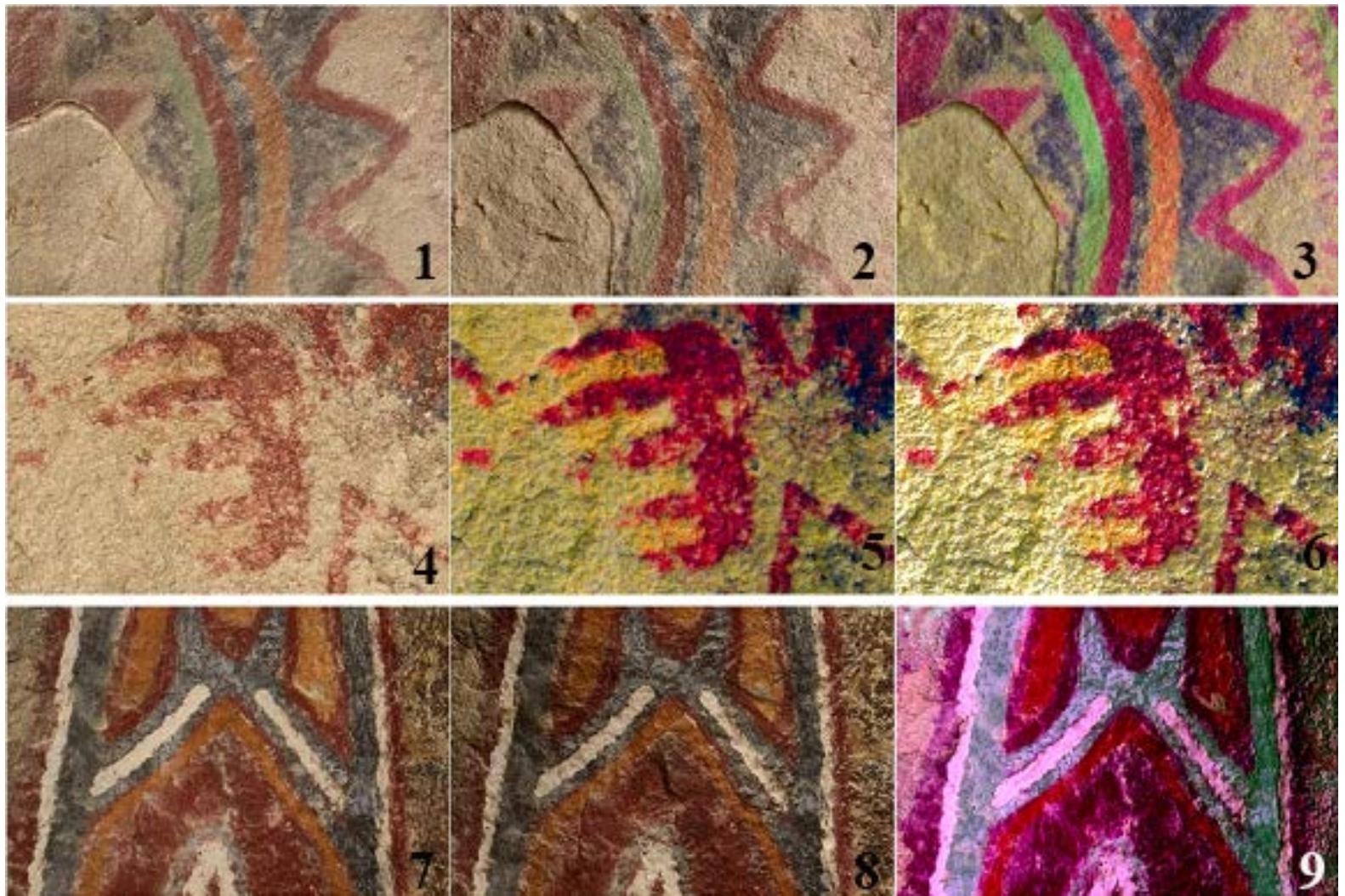

306 Figure 8: Details from Panels D (above), B (middle) and D (below). Digital image $(1,7)$ and 307 RTI visualizations in default mode $(2,4,8)$ and DS RTI renderings in default (3, 5, 9), and 308 specular enhancement mode (6). 

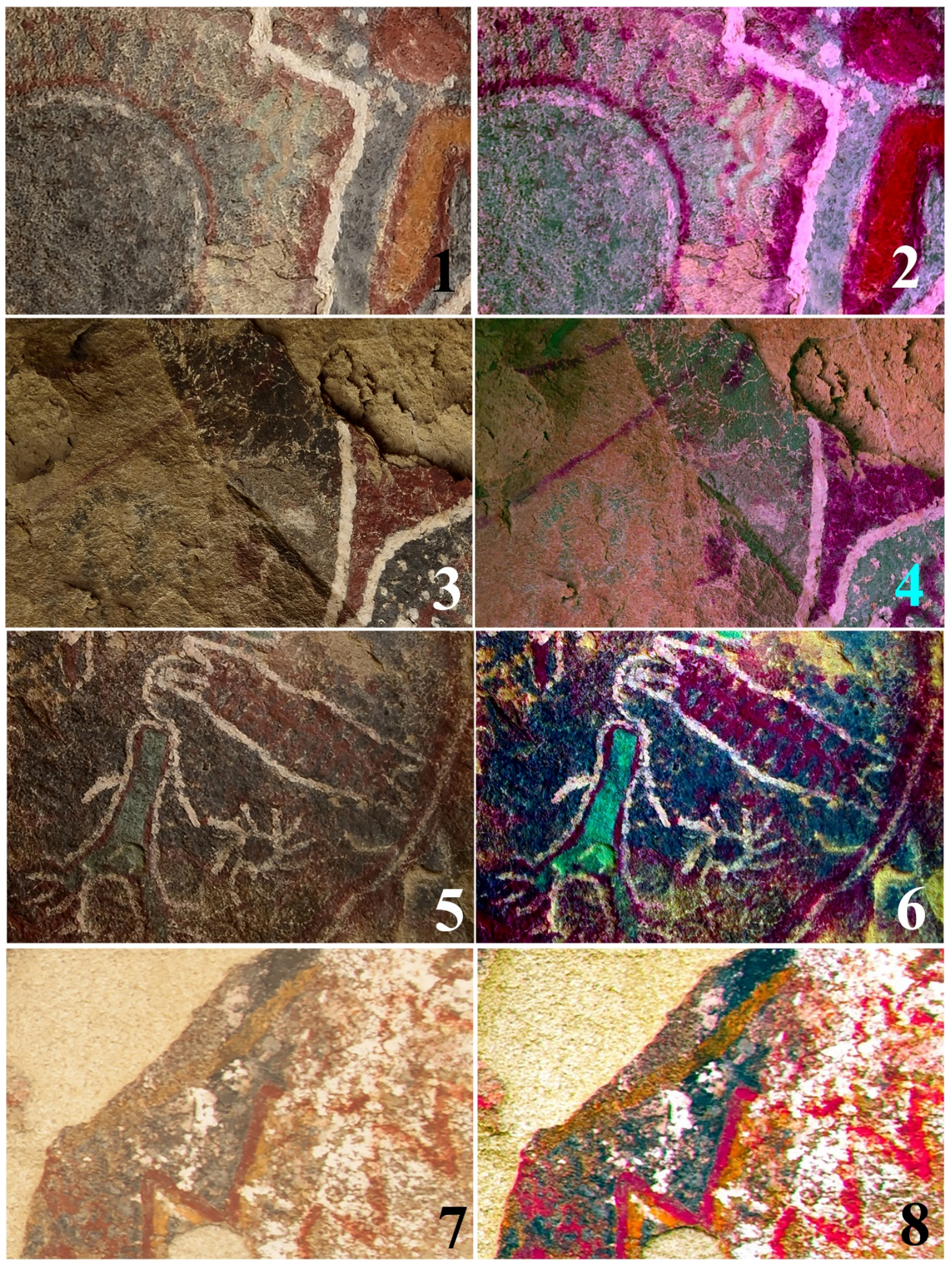

Figure 9: Panels $D, E$, and $B$, details. RTI visualizations in mainstream $(1,3,5,7)$ and $D S$ RTI $(2,4,6,8)$.

\section{A visual grammar for rock art stratigraphic diagrams}

313 Because of the lack of a specialized GraphViz graphical user interface and standardization for 314 rock art stratigraphic visualization, the development of a visual grammar is necessary. For the 
generation of a graph, nodes, lines, edges, and frames should be organized and related in a two-dimensional pictorial space, using a list of attributes specified by the DOT language.

\subsection{The graph layout}

For the general layout of the graph, it is necessary to specify the size, background colour, label/title, and legend. A combination of the attributes ratio and size sets the diagram maximum width and height and the aspect ratio (height/width) and defines its pictorial space, offering the opportunity to force orthogonality. The latter is a parameter that enhances the human usability of diagrams and is useful for presentation and dissemination in printed and digital formats. A ratio 1:1.41 comes in accordance with all the ISO standard papers. A neutral grey tone as the background colour of the pictorial space, set by the bgcolor attribute, is preferable to the white default background since it enables the use of white colour for the representation of other aspects of the painting. The vertical positioning of the timeline on the side of the graph is possible by simply connecting two nodes labelled most recent and earliest, without any further specifications, since DOT graphs follow a direction from top to bottom by default. A node, with appropriate font size, is the diagram's title stating the panel and archaeological site. Auxiliary features are the vertical and horizontal panel, a series of invisible nodes that can be used as guides for the positioning of nodes at a later stage in case of complex stratigraphy. The assignment of above/below stratigraphic relationship aligns the nodes at the vertical axis. The rank attribute aligns the nodes at the horizontal axis. Optionally, a legend, a framed group of nodes, created via the subgraph cluster attribute, explains the visual conventions of the graph. The width, height and shape attribute define the size and shape of the nodes. The len attribute defines the length of the connecting edges. The visibility of nodes and relationships in the final rendering of the diagram depends on the style attribute, which takes the value invis for features added in the graph simply for alignment purposes. For completing the basic layout of the diagram, the addition of concentrate attribute set to true merges relationships, simplifying the graph without minimizing the presented information. By following the above recommendations, a graph layout is generated which includes the title/label with necessary information about the site and the timeline, as well as the appropriate ratio for the pictorial space, in addition to attributes that assist in the successful completion of the graph.

\subsection{Nodes}

Each node corresponds to an individual painting feature, identified via visual inspection or image enhancement, depending on its state of preservation. The outline depends on the colour and style of the painting feature, set by the color. The colours of the paint features are visualized by outline colours. Attempts to use RGB values extracted from digital images of panels for the specification of the colour proved to be unsuccessful, resulting in confusing diagrams because of the variation of colours present. Hence, representing colours in a simplistic generalized mode, grouping darker and lighter tones of similar hues is a meaningful way for diagrammatic visualization. Different outline/border styles visualize diagrammatically the style/method of painting features, categorized as line drawings, full figured and dotted designs, managed by the peripheries attribute followed by a numerical value-specification. A single outline refers to line drawings, double outline refers to fullfigured designs and triple outline refers to dots. The label attribute defines the name of the painting feature and comes in accordance with the naming convention used for the analysis of the panel. It can be replaced by an HTML TABLE specification, for embedding an image of 
the painting feature and its name inside the node, enclosed in the coloured outlined shape. The inserted image represents the painting feature either as it was originally documented in the digital image or as traced drawing or in false colour. By following these recommendations, the user can easily distinguish the colour and style of each pictorial element represented in the graph. This addition of an image corresponding to each pictorial element facilitates easier understanding of the paint sequence and enhances the readability of the graph.

Other than digital image analysis and visual inspection, the integration of physicochemical analysis results is necessary, for a complete diagrammatic visualization of rock art research when using a variety of different analytical approaches. The groupings and the variation of painting features based on their compositional characteristics according to analysis can be represented by assigning different fill colours to the nodes via the fillcolor attribute. Hence, the user can access easily information about the composition of the paint. For a second type of analysis, the groups can be represented by different shapes of nodes via the shape attribute. Undoubtedly, the more techniques are applied for the analysis of paintings the more challenging the generation of the diagrams. The incorporation of two different analytic techniques is possible by manipulating the shape and shading of the nodes. Although DOT is flexible enough and capable for further expansion to include more information, there is the danger to overpopulate the diagram and diminish its communicating power.

\subsection{Edges}

All stratigraphic diagrams visualize relationships between nodes via arrows starting from the above pointing to the below node. Although this clearly explains the painting sequence, it does not provide any further information about the provenance of layering information, which derives from the analysis of texture and colour. The numerical values assigned to stratigraphic relationship as stated in section 3.3. were included in the graph as labels attached to edges. This is possible via the label edge attribute. Moreover, this label is hyperlinked to an RTI snapshot of the particular area of the panel under the appropriate lighting conditions and rendering mode, providing evidence for the stratigraphic relationships. It makes the diagram more understandable and helps users engage with the diagrammatic information in a less conventional and more interactive way. Even in printed format, which provides limited options for interactive analysis, the user can access the relevant visualization by referring to the labels of the edges, which is the only method used so far for interacting with stratigraphic diagrams in an archaeological context.

\subsection{Clusters}

Analysis of superimposition implies the separation of layers through identification of painting events and successive motifs. The diagrammatic approach to layers' separation is the alignment of nodes at the vertical axis, enclosed in frames as groups and subgroups belonging to the same painting event and motif respectively. The former is feasible in DOT using the rank and/or newrank attributes and the latter via subgraph cluster. Additionally, the clusterrank attribute assists in handling clusters. The compound, lhead and ltail attributes which allow edges expanding between clusters and clipped to the boundary of the clusters, are useful for assigning stratigraphic relationships across clusters. The grouping options explained above are particularly useful for interpretation purposes, since they make individual motifs and painting events easily distinguishable among complex superimposed pictographs. 
406 Figure 10 presents a diagram generated following the proposed methodology based on data

407 derived from the Harris Matrix by Gunn et al. for the Nawarla Gabarnmung A3 panel (2010), 408 along with an explanation of the DOT script used to generate the diagram. On the left side of 409 the graph a timeline indicates the orientation of the graph from most recent at the top to the 410 earliest paint features (section A). In section C, pseudo chromatic visualizations of the panel 411 depict the painting history, while on the left bottom corner and image of the panel and its title 412 are located (section B). The painting features are represented in section D. At the top a cluster 413 includes all the white coloured paint features and towards the bottom of the graph another 414 cluster includes the red coloured earlier layer. In the middle of the graph few elements are 415 represented along with their traced images. The outline and colour of every node indicates the 416 colour and style of the paint. Unlike the Harris Matrix published by Gunn et al. for the 417 Nawarla Gabarnmung A3 panel (2010), the diagrammatic visualization generated following 418 the proposed methodology can stand on its own and explains the painting stratigraphy 419 without further information needed. Additionally, it is far more informative because of the 420 stylistic information provided and the embedded images of painting features and successive 421 layers. 


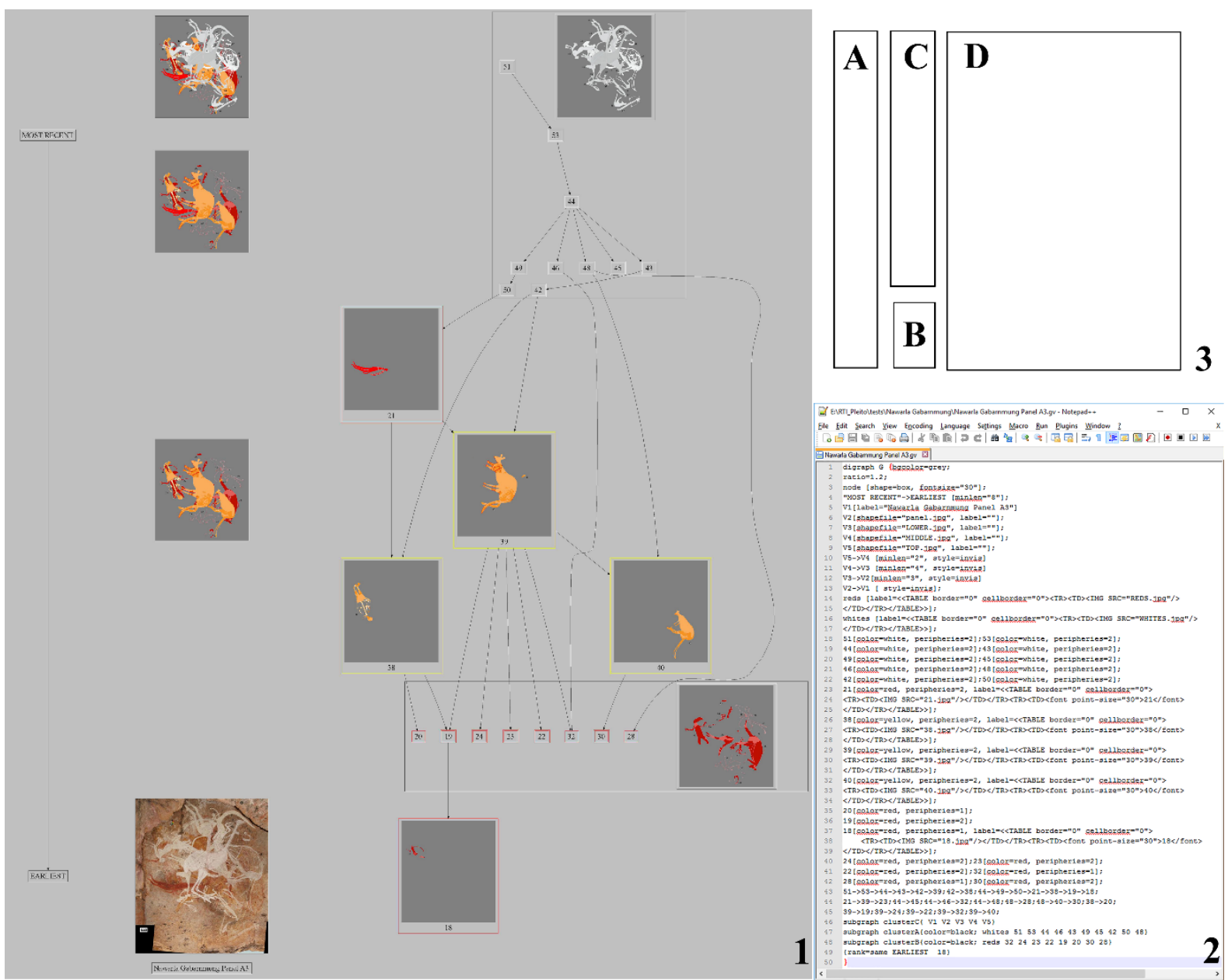

Figure 10: Diagrammatic representation of data published by Gunn et al. for the Nawarla Gabarnmung A3 panel, generated in GraphViz Version 2.6, following the proposed methodology (1). The script used for the generation of diagram (2). Row 1: specifies that the graph is a directed graph, open brackets, set grey as a background colour; row 2: aspect ratio (height/width) set 1.2; row 3: all nodes are rectangular with font size set 30; row 4: defines the relationship between the nodes earliest \& most recent; row 5: the title node; rows 6-9: nodes with embedded images without label; rows 10-13: defines stratigraphic relationships, distance and visibility of nodes v1 v2 v3 v4 v5; rows 14, 15, 21-28, 31-32: indicates colour and style (single or double) for the outline of the nodes. An image and a textual description embedded as a label; rows 16-20, 29, 30, 33-35: indicates color and style (single or double) for the outline of the nodes; rows 36-38: defines stratigraphic relationships. “->” defines above/below nodes, “;” separates relationships; row 39: indicates that nodes v1 v2 v3 v4 v5 belong to same cluster; row 40-41: cluster $a$, $b$. indicates clustered nodes with a solid black frame; row 42: the rank=same attribute indicates that nodes earliest and 18 are aligned in the same rank; row 43: the end of the "directed graph", close brackets. The diagram layout: timeline (A), title with image (B), successive layers presenting the painting history $(C)$, painting features in stratigraphic arrangement $(D)(3)$.

\section{The Pleito cave: Panel C}

The initial phase for the analysis of Panel $\mathrm{C}$ is the identification of 56 individual painting features via DS enhancement, including twelve black features (ybk filter), nine green features (labi filter), five orange features (lye filter), twenty-three red features (yre filter) and seven white features (lbl filter) (Figure 11). The selection of painting features was completed using 
the ROI Manager in ImageJ. Then the appropriate colour and name was assigned to each painting feature. The measure and list utility were used for the generation of an Excel spreadsheet, which provides alphanumeric values of the colour and name for the diagrammatic representation of each feature. For the formatting in excel according to DOT syntax, the color, peripheries and label attribute were assigned to each node. The colour of the feature provides the initial data for the definition of the node. Stylistic information is indicated by different outline styles. The single outline indicates a line drawing, the double outline a full body, and the triple outline the dots. The embedded images maximize the usability of the graphs. Additionally, compositional groups derived from $\mathrm{pXRF}$ analysis were represented diagrammatically via different fill colours. For example, Figure 12 presents five nodes, each one representing a green painting features in four different stages of the 457 diagram's development.

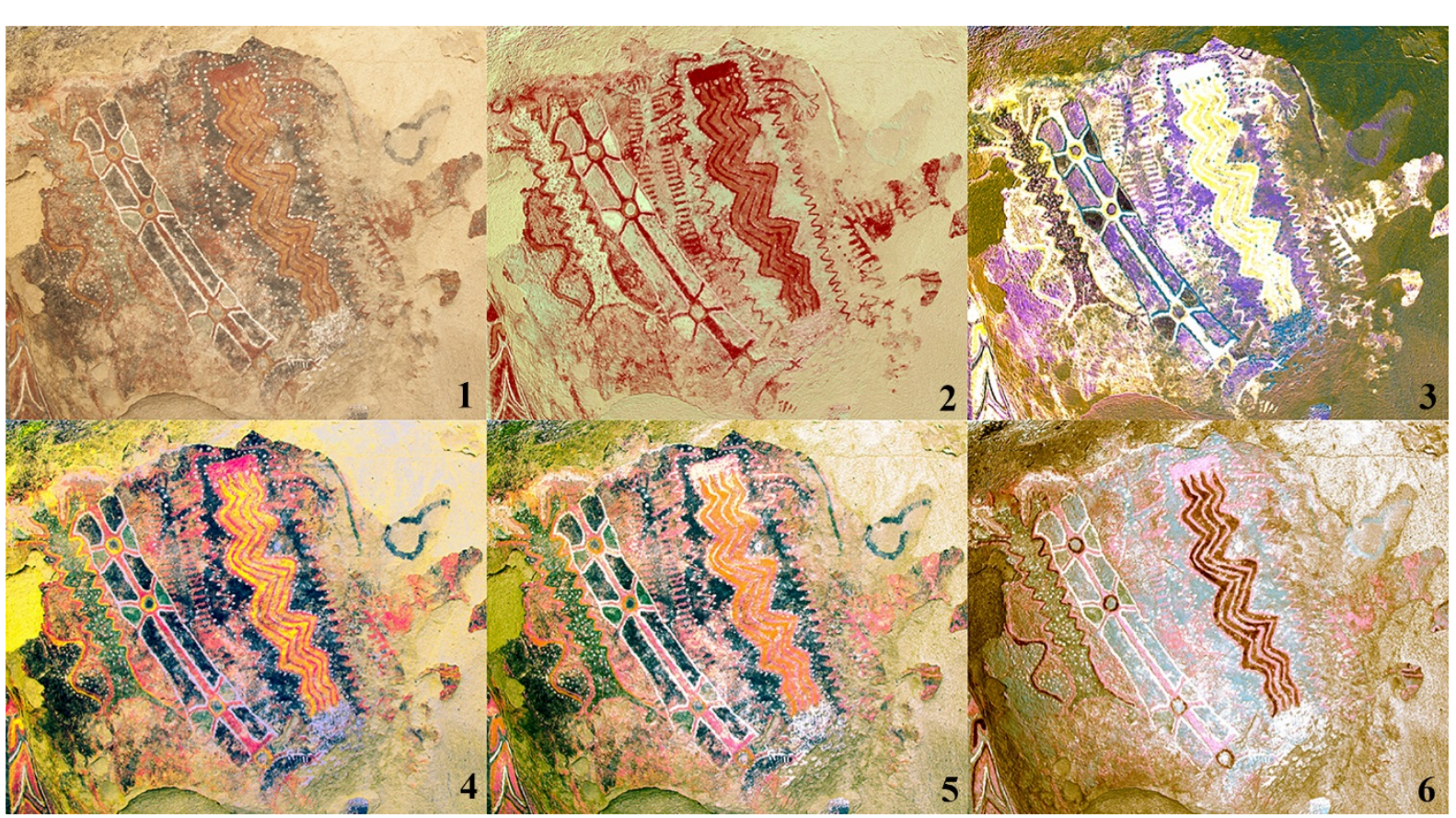

Figure 7: Digital image of Panel C (1) and DS colour enhancement in yre (2), labi (3), ybk (4), lbl (5) and lye (6) mode. 
462

463

464

465

466

467

468

469

470

471

472

473

474

475

476

477

478

479

480

481

482

483

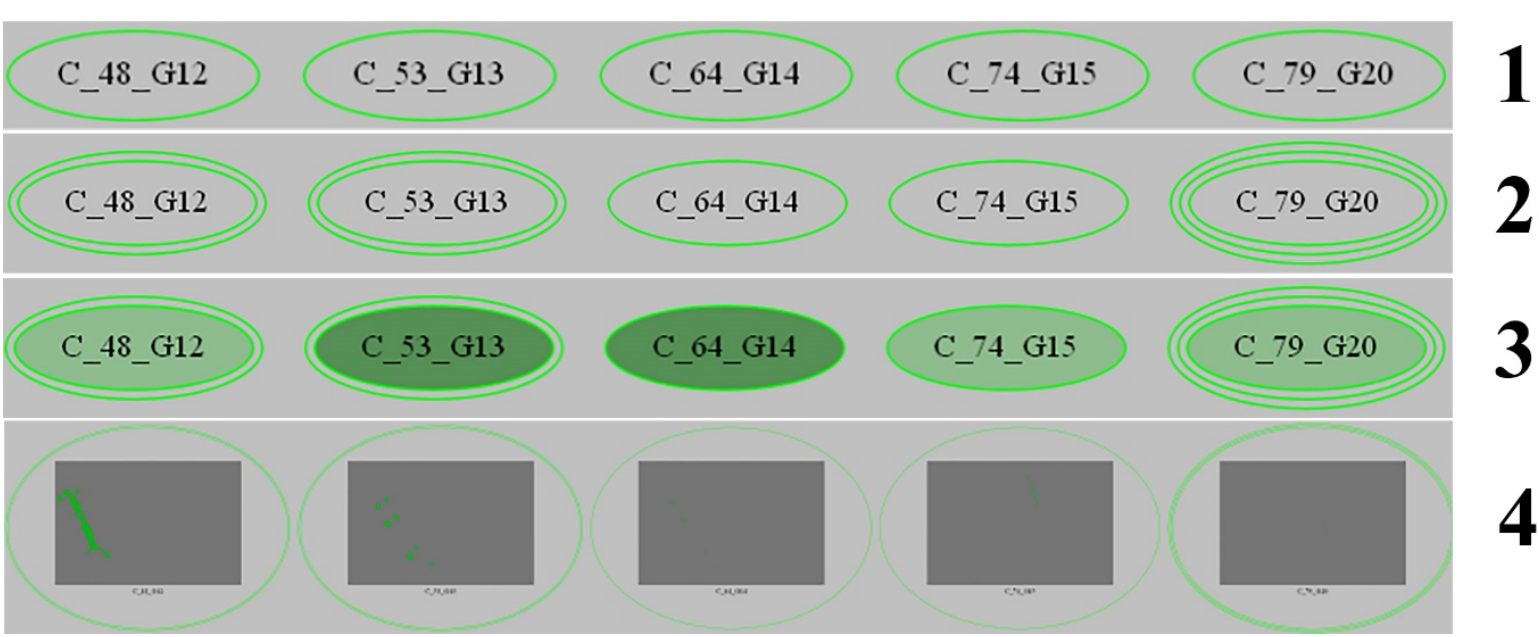

Figure 8: Example of five nodes for green features from Panel $C$ in four different stages of the diagram's development. Simple rectangular nodes represent the colour of the pigment (1). Single, double and triple outlines indicate the style of the design (2). Fill colours represent compositional variations, light green (HEX code \#8fbc8f) indicates compositional group GN1 characterized by the higher proportion of potassium and silicon, darker green (HEX code \#568f56) indicates compositional group GN2 characterized by the higher proportion of iron, calcium and sulfur (3). Nodes with embedded traced images of painting features (4).

Simultaneous comparative analysis of visible/mainstream and false colour RTI (DS RTI) in CHER-Ob software enables bookmarking of views of interest and textual annotations, which forms the basis for the definition of relationships with previous and later features, painted either below or above. For Panel C 52 stratigraphic relationships were identified and recorded in an excel spreadsheet. These stratigraphic relationships are represented diagrammatically as connecting edges with an attached label that refers to specific RTI renderings. For example, the green feature G12 appears below a group of white and red dots (W57 and R140) and above the red sun element (R137) (Figure 13). The green feature G13 appears below the white outline (W58) and above the red foot-like feature (R133). The feature G14 appears below the orange outline (O27) and above the black detail (B36). As shown in Fig. 14.2, the fill colours for the nodes G13 and G14 are identical, indicating a similar composition (Figure 14). 

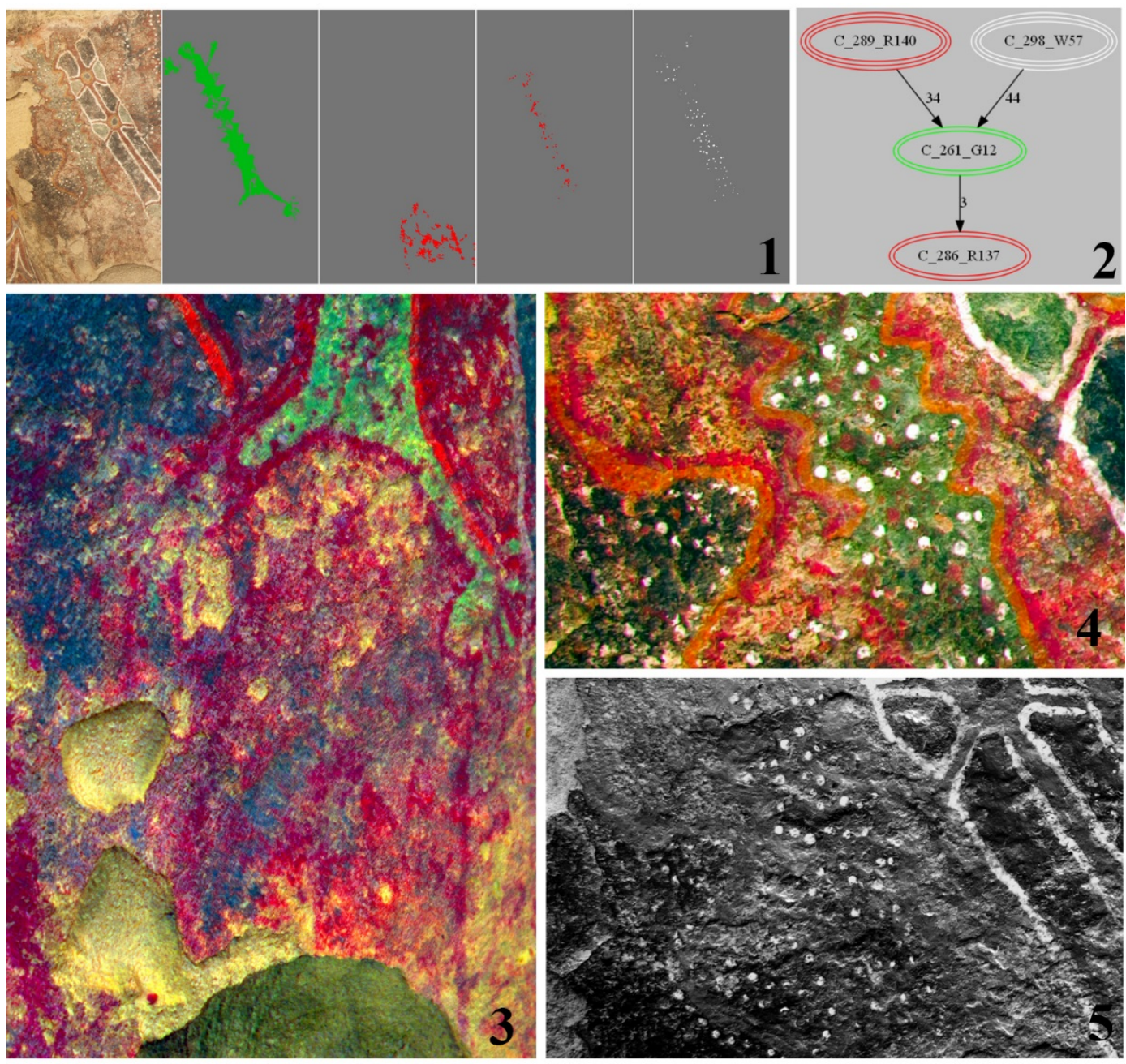

Figure 13: Detail of Panel C (1). Features G12, R137, R140 and W57 (from left to right). (3) marked as stratigraphic relationship No 3. DS RTI rendering emphasizing the presence of the red dots (R140) marked as the stratigraphic relationship No 34 (4). RTI rendering in

489 specular enhancement mode revealing the texture of the white dots (W57) as the most 490 dominant paint feature marked as the stratigraphic relationship No 44 (5). 

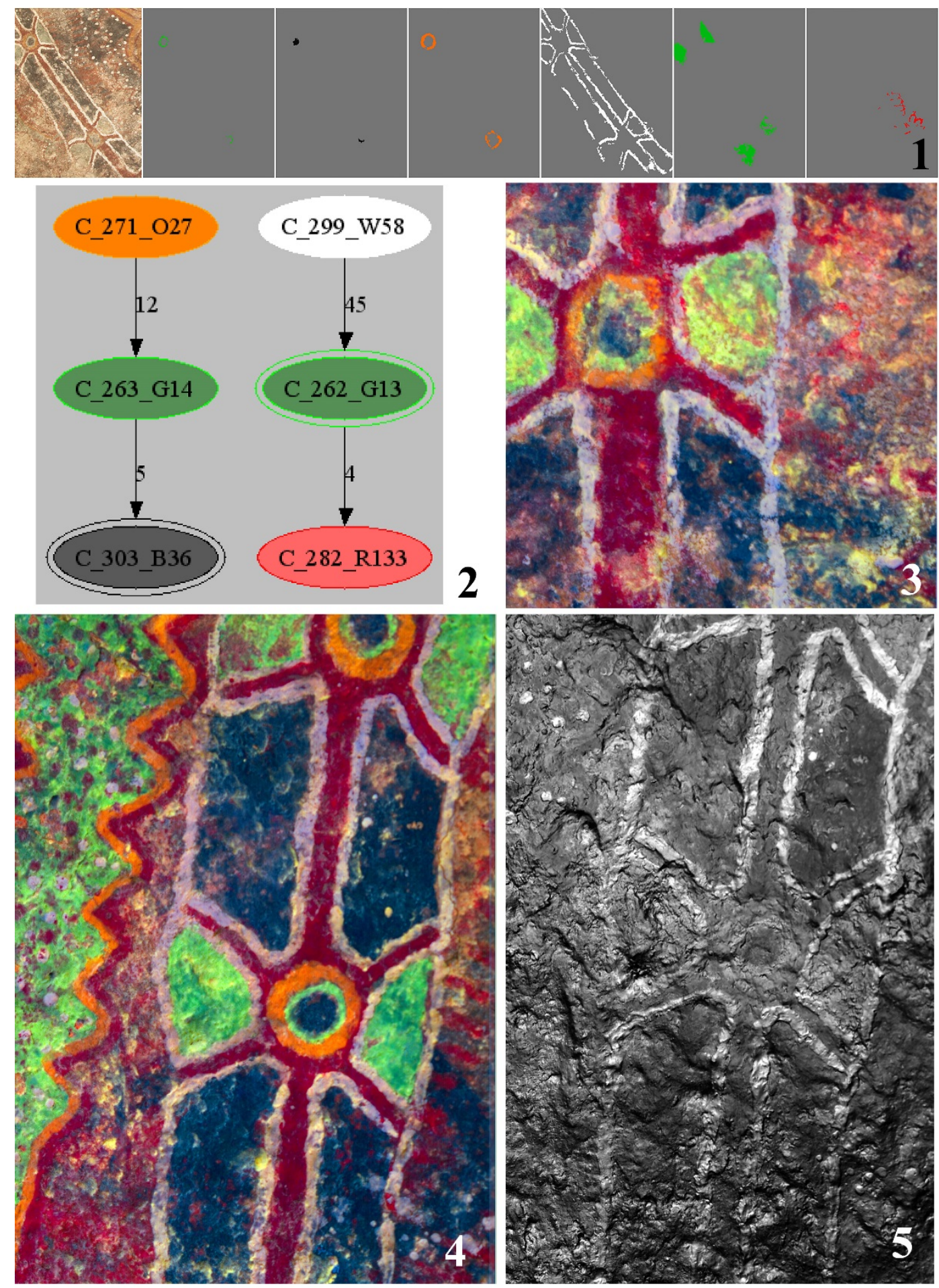

Figure 9: Detail of Panel C (1). Features G14, B36, O27, W58, G13, and R133 (from left to right). Diagram (2). DS RTI rendering enhancing the visualization of the faded red element R133 below the green element, marked as stratigraphic relationship No 4 (3). DS RTI rendering showing the sequence of orange (027), green (G14) and black (B36) elements, marked as stratigraphic relationships No 12 and 5 (4). RTI rendering in specular enhancement mode revealing the texture of the white lines (W58) above the green element, marked as the stratigraphic relationship No 45 (5). 
The already presented examples from details of Panel $\mathrm{C}$ highlight the potential of the stratigraphic diagrams for integration of diverse datasets, including pigments analysis, digital image enhancement and interactive relighting. Furthermore, the diagrammatic visualization method proposed assist in the detection of patterns. These patterns may be relevant to the colours and pigments used as well as the painting style. For example, as shown in Fig. 15 which presents the diagrammatic visualization of Panel C, black coloured features represented by grey filled nodes with black outlines, tend towards the earlier layers while greens are found in the middle layers. Orange and white coloured features are located at most recent layers of the panel. Red coloured features exist in all layers other than the most recent and earliest ones. Regarding the stylistic comparison of features across layers, the diagram reveals that dotted features, indicated by triple outline nodes are mainly part of most recent layers. Line drawings, indicated by single outlines, exist in middle and most recent layers. Earlier layers tend to have more full body designs, indicated by double outlines. Pigments were categorised in compositional groups, formed using comparisons of elemental composition based on XRF data. All the red painting features had high iron counts in the pXRF spectra, but showed variation in their counts of other elements. In particular variation was seen in the relative proportions of sulphur and calcium counts. Red painting features indicated by pink fill colour have higher sulphur counts relative to iron and are located in middle layer. There is a large concentration of red painting features with relatively high calcium counts, indicated by the bright red fill colour, in the middle layers. On the contrary, iron rich reds with lower calcium and sulphur counts, indicated by dark red fill colour are lustered in earlier and most recent layers (Figure 15). The detection of these patterns was made possible by observing the diagrammatic representation generated following the proposed methodology, but it would have been particularly difficult and time consuming using conventional Harris Matrixes. 


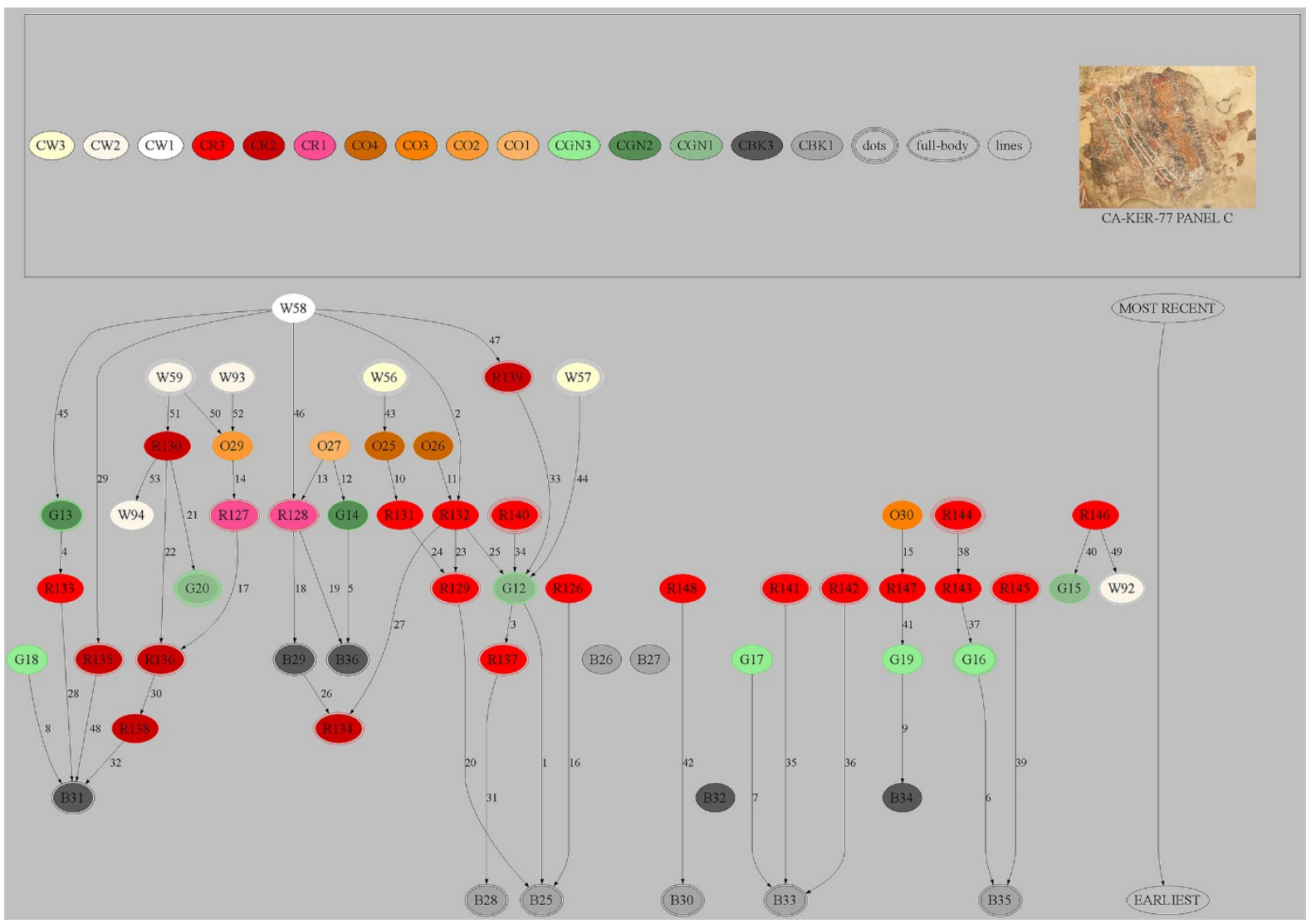

528 Figure 15: Diagrammatic representation of Panel C.

529

530

531

532

533

534

535

536

537

538

539

540

541

542

543

544

545

Additionally, diagrams are useful for communication of ideas and insights, and interpretative approaches. The most powerful means to interpret the integrated data is to identify paint features that form separate painting episodes and represent them as subgraphs. In such way, the graph consists of a series of clusters, with the option to include traced images of the features and motifs, which express the biography of the painting. The clusters are independent of the node definition and stratigraphic information, which is based completely on data. Hence, expressing different and maybe conflicting ideas for the development of the painting via clustering is possible. For example, Figure 16 presents a cluster of a design in Panel C, which is anthropomorphic (or 'transmorphic', see Robinson, 2013b). The ranking of nodes indicates the painting stratigraphy, their outline provides information for the colour and style. The fill colour defines compositional similarities and differences. The embedded images make it easier for the user to identify individual painting features. The image on the top of the cluster shows the painting episode and separates it from neighbour features visually via false colour visualization. Manipulating and altering the DOT file, which contains the script for the generation of the graphs, is feasible. Similarly, generating a different rendering of the same diagram is achieved by turning off certain attributes via the addition of the symbol */. 


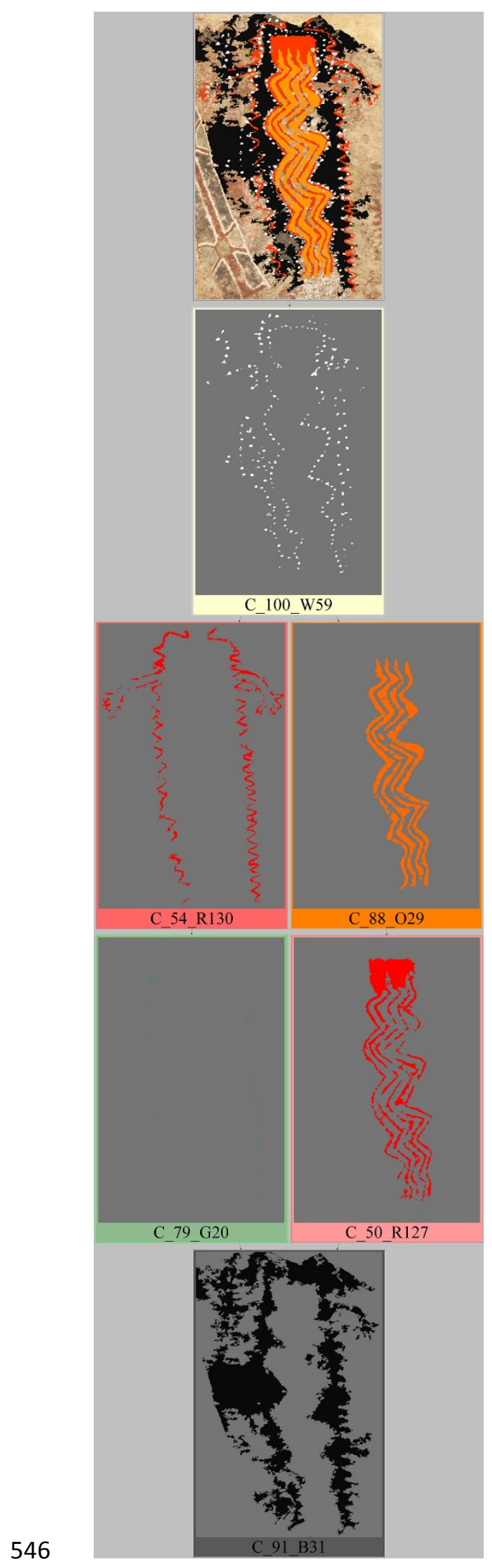

547 Figure 10: The cluster diagram of an anthropomorphic design in Panel C. 
The sequence detailed above enables us to reconsider Lee's hypothesis that exotic pigments were derived from the missions and Whitley's idea that the paintings were discrete events depicting shamanic self-portraits. First, if the pigments were derived from the missions, we would expect the greens to have been copper based (see Neuerburg 1991: 6, Webb 1945: 143-144) and for them to occupy the later and final sequences of painting. However, the analytical work in Panel C has found no copper elements in the readings, and the green occupies the middle sequences. This indicates that green is an indigenous paint and was employed during the prehistoric use of the site rather than historical period. This idea is supported by Scott et al's (2002) work on exfoliated fragments from the site, which also detected no copper in the greens even though a green azurite is locally available (see Reeves et al. 2009 for expanded discussion). Importantly, the sequencing of Panel C shows complex phases, with earlier layers represented by an undifferentiated black followed by red geometric shapes. These do not match Whitley's interpretation of shamanic bodily transformations. The later compositions do show elongated anthropomorphic figures. However, it is clear that rather than being discrete singular paintings, the compositions inter-reference earlier black layers. The analytical also work shows a variety of different reds and greens were employed, suggesting different paint sources and/or different admixtures rather than a single source. This reinforces the idea that different pigment recipes represent the act of different authors. This indicates that the 'final' images we are seeing are the accumulation of different artist's sequential contributions, thus suggesting that they are not singular self-portraits by an individual shaman but instead are multi-authored compositions, likely to be some form of temporal interplay perhaps between generations of artists.

\section{Conclusions}

In conclusion, this paper presented a method for recording, documentation, analysis and diagrammatic representation of diverse dataset derived from rock art research. This method employs digital image enhancement for identification of pictorial elements (1), in synergy with interactive relighting for exploring stratigraphy and layering of pictographs (2) and DOT scripts rendered in GraphViz for the diagrammatic representation of imaging and analytical data (3). Furthermore, this study evaluated the potential of RTI for the recording, documentation, analysis and dissemination of rock art. The main areas of interest for the visual virtual analysis of pictographs are the condition assessment, the study of rock morphology, paint characteristics and stratigraphy. In the case of faded and thin colour layers and/or complex superimposed pictographs, the application of DS RTI, via the introduction of a preprocessing phase for the RTI dataset, proved to be a significant improvement as shown in the examples.

Additionally, the proposed methodology allows the generation of diagrams in different file formats after modifications of alphanumerical data in accordance with DOT syntax. The proposed flexible approach manages to diagrammatically integrate and at the same time distinguish information derived from different imaging techniques such as colour enhancement and interactive relighting, as well as XRF analysis. Other analytic techniques can be integrated as well. Options for tracking down the provenance of the visualized stratigraphy are included. Significantly, it is the only diagrammatic representation proposed in an archaeological context so far that incorporates images and drawings within the diagram automatically without the need for further processing. The ability to access information for the compositional, stylistic and stratigraphic information as well as images of painting 
features in a single diagram is one of the greater strengths of the proposed methodology. Moreover, a core concept of the proposed approach is the use of the diagram beyond data visualization and integration as a tool for further analysis and interpretation. Diagrammatic visualizations made it possible to identify patterns regarding the use of colours and shapes throughout the stratigraphy of the Panel, as shown in the case of Panel C. The rock art researcher can identify and communicate ideas about motifs, develop visual narratives about the individual painting events by manipulations of nodes in clusters as subgraphs. These are possible by following the developed visual grammar, which is flexible and can be downsized or expanded and further developed according to the requirements of each rock art project. As shown in our unpacking of Lee's and Whitley's hyphotheses, this methodology enables the revisiting of unresolved questions while developing new interpretations of the rock art and the site itself. Last but not least, hardware and software requirements for data acquisition, processing, analysis of images and for the generation of the diagrams are minimum and completely based on open-access systems.

\section{Acknowledgments}

This study was funded by the Arts and Humanities Research Council (AHRC) grant 'Unravelling the Gordian Knot: Integrating Advanced Portable Technologies into the Analysis of Rock Art Superimposition' (Grant no. AH/L014041/1). Thanks to Dan York and the staff of the Wind Wolves Preserve. Special thanks to the Tejon Tribe, including Mark Sanchez, Sandra Hernandez, and Colin Rambo. Thanks to Dr Bruce Kaiser and Andrea Tullos at Bruker International, for their advice, support and provision of equipment. The 3D model of the cave, used for the generation of sections for Figure 6, was provided by Devlin Gandy.

\section{References}

Artal-Isbrand, P., Klausmeyer, P., 2015. Using Reflectance Transformation Imaging and 3D Laser Scanning Confocal Microscopy to Evaluate Relief and Contour Lines on Ancient Attic Greek Vases. Micros. Today 23, 30-35. doi:10.1017/S1551929515000565

Barros García, J.M., 2009. Recording stratigraphic relationships among non-original deposits on a 16th century painting. J. Cult. Herit. 10, 338-346. doi:10.1016/j.culher.2009.01.001

Beale, G., Pagi, H., Earl, G., 2013. Roman painted statue head from Herculaneum, in: Duffy, S.M. (Ed.), Multi-Light Imaging for Heritage Applications. English Heritage, Swindon, pp. 19-20.

Bedford, C., Robinson, D., Perry, J., Baker, M., Miles, J., Kotoula, E., Gandy, D., Bernard, J., 2016. Unravelling the Gordian knot - Combining technologies to analyse rock art in Pleito cave, in: Ruby, A., Laylander, D. (Eds.), Proceedings of the Society for California Archaeology, Volume 30. Society for California Archaeology, Ontario, California, pp. 183195.

Booch, G., Rumbaugh, J., Jacobson, I., 1999. The Unified Modeling Language User Guide, second. ed. Addison-Wesley, Reading. 
Carver, G., 2013. ArcheoInf , the CIDOC-CRM and STELLAR: Workflow , Bottlenecks , and Where do we Go from Here?, in: Earl, G., Sly, T., Chrysanthi, A., Murrieta-Flores, P., Papadopoulos, C., Romanowska, I., Wheatley, D. (Eds.), Proceedings of the 40th Conference in Computer Applications and Quantitative Methods in Archaeology. Amsterdam University Press, Amsterdam, pp. 498-508.

Cerrillo-Cuenca, E., Sepúlveda, M., 2015. An assessment of methods for the digital enhancement of rock paintings: The rock art from the precordillera of Arica (Chile) as a case study. J. Archaeol. Sci. 55, 197-208. doi:10.1016/j.jas.2015.01.006

Chippindale, C., De Jongh, J., Flood, J., Rufolo, S., 2000. Stratigraphy, Harris matrices \& relative dating of Australian rock-art. Antiquity 74, 285-286. doi:10.1017/S0003598X00059275

Cobb, S., 2016. 3D PITOTI: 3D acquisition, processing and presentation of prehistoric European rock-art. http://www.3d-pitoti.eu/ (accessed 31/8/2017)

Costa, S., 2007. Harris Matrix with Graphviz. http://www.iosa.it/2007/12/18/harris-matrixwith-graphviz/ (accessed 8.31.17).

Cultural Heritage Imaging, 2013a. Guide to highlight image capture v2.0. http://culturalheritageimaging.org (accessed 1.19.14).

Cultural Heritage Imaging, 2013b. Guide to RTIViewer, version 1.1. http://culturalheritageimaging.org/What_We_Offer/Downloads/rtiviewer/RTIViewer_Guide_ v1_1.pdf (accessed 7.2.14).

Cultural Heritage Imaging, 2011. Guide to highlight image processing. http://culturalheritageimaging.org/What_We_Offer/Downloads/rtibuilder/RTI_hlt_Processin g_Guide_v14_beta.pdf (accessed 4.3.12).

De Roo, B., Stal, C., Lonneville, B., De Wulf, A., Bourgeois, J., De Maeyer, P., 2016. Spatiotemporal data as the foundation of an archaeological stratigraphy extraction and management system. J. Cult. Herit. 19, 522-530. doi:http://dx.doi.org/10.1016/j.culher.2015.12.001

Defrasne, C., 2014. Digital image enhancement for recording rupestrian engravings: Applications to an alpine rockshelter. J. Archaeol. Sci. 50, 31-38. doi:10.1016/j.jas.2014.06.010

Díaz-Guardamino, M., García Sanjuán, L., Wheatley, D., Rodríguez Zamora, V., 2015. RTI and the study of engraved rock art: A re-examination of the Iberian south-western stelae of Setefilla and Almadén de la Plata 2 (Seville, Spain). Digit. Appl. Archaeol. Cult. Herit. 2, 4145. doi:10.1016/j.daach.2015.07.002

Domingo, I., Carrión, B., Blanco, S., Lerma, J.L., 2015. Evaluating conventional and advanced visible image enhancement solutions to produce digital tracings at el Carche rock art shelter. Digit. Appl. Archaeol. Cult. Herit. 2, 79-88. doi:10.1016/j.daach.2015.01.001 
670 Duffy, S.M., Bryan, P., Earl, G., Beale, G., Pagi, H., Kotoula, E., 2013. Multi-light Imaging

671 for Heritage Applications. English Heritage, Swindon.

672 Duffy, S.M., 2010. Polynomial texture mapping at Roughting Linn rock art site, in: Mills, J.

673 P., Barber, D. M., Miller, P.E., Newton, I. (Eds), Proceedings of the ISPRS Commission V

674 Mid-Term Symposium 'Close Range Image Measurement Techniques'. International

675 Archives of the Photogrammetry, Remote Sensing and Spatial Information Sciences,

676 Newcastle upon Tyne, pp. 213-217.

677 Eades, P., 2014. What is a good diagram? (Revisited), in: Fleming, S.D., Fish, A., Scaffidi, C.

678 (Eds), Proceedings of 2014 IEEE Symposium on Visual Languages and Human-Centric

679 Computing (VL/HCC). IEEE, Melbourne, pp. 1-2.

680 Ferreira, T., Rasband, W., 2012. ImageJ User Guide: IJ 1.46r. National Institute of Health,

681 Bethesda. doi:10.1038/nmeth.2019

682 Fritz, C., Willis, M.D., Tosello, G., 2016. Reconstructing Paleolithic cave art: The example of

683 Marsoulas Cave (France). J. Archaeol. Sci. Reports 10, 910-916.

684 doi:http://dx.doi.org/10.1016/j.jasrep.2016.05.012

685 Gabov, A., Bevan, G., 2011. Recording the weathering of outdoor stone monuments using

686 reflectance transformation imaging (RTI): the case of the Guild of All Arts (Scarborough,

687 Ontario). J. Can. Assoc. Conserv. = J. l'Association Can. pour la Conserv. la Restaur. 36, 3-

68814.

689 Gansner, E., Koutsofios, E., North, S., 2015. Drawing graphs with dot.

690 www.graphviz.org/pdf/dotguide.pdf (accessed 8.31.17).

691 Goel, A., Jamnik, M., Narayanan, N., 2010. Diagrammatic representation and inference.

692 Springer, Berlin.

693 Grant, C., 1965. The rock paintings of the Chumash, University of California Press, Berkeley.

694 Gunn, R.G., Ogleby, C.L., Lee, D., Whear, R.L., 2010. A method to visually rationalise 695 superimposed pigment motifs. Rock Art Res. 27, 131-136.

696 Harman, J., 2008. DStretch. http://www.dstretch.com/AlgorithmDescription.html (accessed $69731 / 1 / 2017)$

698 Harris, E.C., 1989. Principles of archaeological stratigraphy, second. ed. Academic Press, San 699 Diego, CA.

700 Herzog, I., 2004. Group and conquer, a method for displaying large stratigraphic data sets, in:

701 Wien, M. der S., Erbe, R.K., Wien, S. (Eds.), The E-Way into the Four Dimensions of

702 Cultural Heritage. CAA 03: Proceedings of the 31st Conference Computer Applications and

703 Quantitative Methods in Archaeology. BAR International Series 1227, Vienna, pp. 423-426.

704 Hundack, C., Mutzel, P., Pouchkarev, I., Reitgruber, B., Schuhmacher, B., Thome, S., 1998.

705 ArchEd: A program for drawing Harris Matrices. 
https://www.ac.tuwien.ac.at/files/archive/ArchEd/ArchEd_UsersGuide.pdf (accessed 31/1/2017)

Vergès-Belmin, V (Ed.), 2008. The ISCS-ICOMOS illustrated glossary on stone deterioration patterns, ICOMOS, Paris.

Jones, A.M., Cochrane, A., Carter, C., Dawson, I., Díaz-Guardamino, M., Kotoula, E., Minkin, L., 2015. Digital imaging and prehistoric imagery: a new analysis of the Folkton Drums. Antiquity 89, 1083-1095. doi:10.15184/aqy.2015.127

Khoury, M., 2013. Let's Draw a Graph : An Introduction with Graphviz. Technical Report No. UCB/EECS-2013-176, University of California at Berkeley, Berkeley. http://www.eecs.berkeley.edu/Pubs/TechRpts/2013/EECS-2013-176.html

Kotoula, E., 2016. Reflectance Transformation Imaging Beyond the Visible: Ultraviolet Reflected and Ultraviolet Induced Visible Fluorescence, in: Campana, S., Scopigno, R., Carpentiero, G., Cirillo, M. (Eds.), CAA2015 Keep the Revolution Going, Proceedings of the 43rd Annual Conference on Computer Applications and Quantitative Methods in Archaeology. Archaeopress Publishing LTD, Siena, Italy, pp. 909-918.

Kotoula, E., Earl, G., 2015. Integrated RTI Approaches for the Study of Painted Surfaces, in: Giligny, F., Djindjian, F., Costa, L., Moscati, P., Robert, S. (Eds.), CAA2014 21st Century Archeaology Concepts, Methods and Tools Proceedings of the 42nd Annual Conference on Computer Applications and Quantitative Methods in Archaeology. Archaeopress Archaeology, Paris, France, pp. 123-134.

Lehoux, D., 2013. Ancient Science in a Digital Age. Isis 104, 111-118. doi:10.1086/669892 Lee, Georgia. 1979. The San Emigdio Rock Art Site. Journal of Californai and Great Basin Anthropology 1(2):295-305.

Malzbender, T., Gelb, D., Wolters, H., 2001. Polynomial texture maps, in: Pocock, L. (Ed.), Proceedings of the 28th Annual Conference on Computer Graphics and Interactive Techniques. ACM, New York, pp. 519-528.

McDonald, J., Catacora, A., de Koning, S., Middleton, E., 2016. Digital technologies and quantitative approaches to recording rock art in the Great Basin, USA. J. Archaeol. Sci. Reports. doi:10.1016/j.jasrep.2016.03.052

Mguni, S., 1997. The evaluation of the superpositioning sequence of painted images to infer relative chronology: Diepkloof Kraal shelter as a case study. University of Cape Town, Cape Town.

Milner, N., Bamforth, M., Beale, G., Carty, J., Chatzipanagis, K., Croft, S.C.K., Conneller, C., Elliott, B.J., Fitton, L.C., Knight, B., Kroger, R., 2016. A unique engraved shale pendant from the site of Star Carr: the oldest Mesolithic art in Britain. Internet Archaeol. 40. https://doi.org/10.11141/ia.40.8

Moktefi, A., Shin, S.-J. (Eds.), 2013. Visual Reasoning with Diagrams. Springer Birkhäuser, New York. doi:10.1007/978-3-0348-0600-8 
Motz, C., Carrier, S.C., 2013. Paperless Recording at the Sangro Valley Project, in: Earl, G., Sly, T., Chrysanthi, A., Murrieta-Flores, P., Papadopoulos, C., Romanowska, I., Wheatley, D. (Eds.), Proceedings of the 40th Conference in Computer Applications and Quantitative Methods in Archaeology. Amsterdam University Press, Amsterdam, pp. 25-30.

Mudge, M., Malzbender, T., Schroer, C., Lum, M., 2006. New Reflection Transformation Imaging Methods for Rock Art and Multiple-Viewpoint Display, in: Ioannides, M., Arnold, D., Niccolucci, F., Mania, K. (Eds.), VAST: International Symposium on Virtual Reality, Archaeology and Intelligent Cultural Heritage. The Eurographics Association, Nicosia, pp. 195-202. doi:10.2312/VAST/VAST06/195-202.

Mudge, M., Voutaz, J.-P., Schroer, C., Lum, M., 2005. Reflection Transformation Imaging and Virtual Representations of Coins from the Hospice of the Grand St. Bernard, in: Mudge, M., Ryan, N., Scopigno, R. (Eds.), The 6th International Symposium on Virtual Reality, Archaeology and Cultural Heritage-VAST. The Eurographics Association, Pisa, pp. 29-39. doi:10.2312/VAST/VAST05/029-039.

Neuerburg, Norman. 1991. The Decoration of the California Missions. Bellephon; Santa Barbara.

Padfield, J., Saunders, D., Malzbender, T., 2005. Polynomial Texture Mapping: A New Tool for Examining the Surface of Paintings, in: Bridgland, J. (Ed.) ICOM-CC fourteenth triennial meeting, The Hague, 12-16 September 2005, Committee for Conservation: preprints. James and James/Earthscan, London, pp. 504-510.

Poier, G., Seidl, M., Zeppelzauer, M., Reinbacher, C., Schaich, M., Bellando, G., Marretta, A., Bischof, H., 2016. PetroSurf3D - A high-resolution 3D Dataset of Rock Art for Surface Segmentation. arXiv preprint https://arxiv.org/abs/1610.01944 (accessed 31/8/2017)

Reeves, Daniel J., Rick Bury, and David W. Robinson. 2009. Invoking Occam’s razor: experimental pigment processing and an hypothesis concerning Emigdiano Chumash rock art. Journal of California and Great Basin Anthropology 29(1):59-67.

Riris, P., Corteletti, R., 2014. A new record of pre-Columbian engravings in Urubici (SC), Brazil using polynomial texture mapping. Internet Archaeol. 38.

Robert, E., Petrognani, S., Lesvignes, E., 2016. Applications of digital photography in the study of Paleolithic cave art. J. Archaeol. Sci. Reports 10, 847-858.

doi:10.1016/j.jasrep.2016.07.026

Robinson, D.W., Baker, M.J., Bedford, C., Perry, J., Wienhold, M., Bernard, J., Reeves, D., Kotoula, E., Gandy, D., Miles, J., 2015. Methodological considerations of integrating portable digital technologies in the analysis and management of complex superimposed Californian pictographs: From spectroscopy and spectral imaging to 3-D scanning. Digit. Appl. Archaeol. Cult. Herit. 2, 166-180. doi:10.1016/j.daach.2015.06.001

Robinson, D.W., 2013a. Drawing Upon the Past: Temporal Ontology and Mythological Ideology in South-central Californian Rock Art. Cambridge Archaeol. J. 23, 373-394. doi:10.1017/S0959774313000310

Robinson, D.W., 2013b. Transmorphic Being, Corresponding Affect: Ontology and RockArt in South-Central California, in: Alberti, B., Jones, A., Pollard, J. (Eds.) Archaeology 
After Interpretation: returning materials to archaeological theory. Left Coast Press, Walnut Creek, California, pp. 59-78.

Rogerio-Candelera, M.Á., 2016. Digital image analysis-based strategies for quantitative monitoring of rock art sites. J. Archaeol. Sci. Reports 10, 864-870. doi:10.1016/j.jasrep.2016.06.041

Rogerio-Candelera, M.Á., 2015. Digital image analysis based study, recording, and protection of painted rock art. Some Iberian experiences. Digit. Appl. Archaeol. Cult. Herit. 2, 68-78. doi:10.1016/j.daach.2014.11.001

Scott, David A., Stephanie Scheerer, and Daniel J. Reeves. 2002. Technical examination of some rock art pigments and encrustations from the Chumash Indian site of San Emigdio, California. Studies in Conservation 47(3): 184-194.

Sharpe, K., Barnett, T., 2008. Recording England's Rock Art: A handbook for Project Officers. English Heritage, Durham City Council, Northumberland County Council. http://archaeologydataservice.ac.uk/catalogue/era836/dissemination/pdf/ERA_Recording_Handbook.pdf (accessed 31/8/2017)

Shi, W., Kotoula, E., Akoglu, K., Yang, Y., Rushmeier, H., 2016. CHER-Ob : A Tool for Shared Analysis in Cultural Heritage, in: Catalano C.E., De Luca, L. (Eds), GCH '16 Proceedings of the 14th Eurographics Workshop on Graphics and Cultural Heritage. The Eurographics Association, Genova, pp. 187-190. https://doi.org/10.2312/gch.20161404

Sikora, J., Sroka, J., Tyszkiewicz, J., 2016. Strati5 - Open Mobile Software for Harris Matrix, in: Campana, S., Scopigno, R., Carpentiero, G., Cirillo, M. (Eds.), CAA2015 Keep the Revolution Going, Proceedings of the 43rd Annual Conference on Computer Applications and Quantitative Methods in Archaeology. Archaeopress Publishing LTD, Siena, Italy, pp. 1005-1014.

Traxler, C., Neubauer, W., 2008. The Harris Matrix Composer - A New Tool to Manage Archaeological Stratigraphy, in: Ioannides, M., Addison, A., Georgopoulos, A., Kalisperis L. (Eds.), Proceedings of the 14th International Conference on Digital Heritage, Virtual Systems and Multimedia. Archaeolingua, Limassol, pp. 13-20.

Tversky, B., 2014. Visualizing Thought, Handbook of Human Centric Visualization, in: W. Huang (ed.), Handbook of Human Centric Visualization. Springer, New York, pp. 3-40.

Watts, S., Owen-Hughes, H., Laing, A., Staniforth, S., Towle, A., 2002. The Power of the Matrix: the application of archaeological stratigraphy to the interpretation of complex paintings, in: Vontobel, R. (Ed.) Preprints of the 13rd Triennial Meeting, Rio de Janeiro, 22 27 September. James and James, London, pp. 479-485.

Webb, Edith. 1945. Pigments used by the Mission Indians of California. The Americas 2(2):137-150.

Whitley, David S. 2000. The Art of the Shaman: Rock Art of California. Salt Lake City: University of Utah Press. 